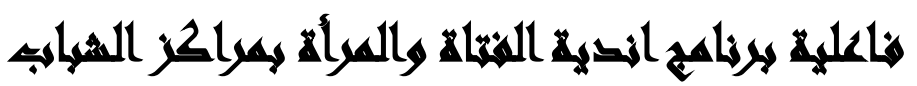

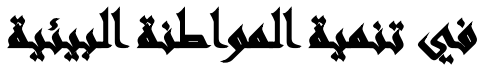

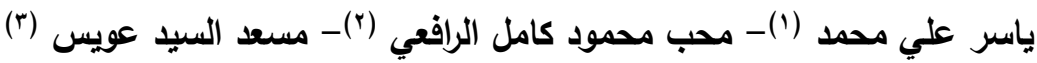

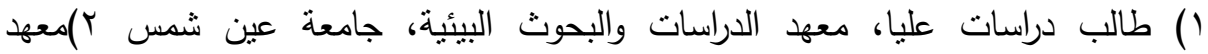
الدراسات والبحوث البيئية، جامعة عين شمس بال كلية التربية الرياضية، جامعة حلوان

\section{المستخليس}

هدف البحث الحالي التعرف على مدى فاعلية برنامج اندية الفتاة والمرأة بمراكز الثباب

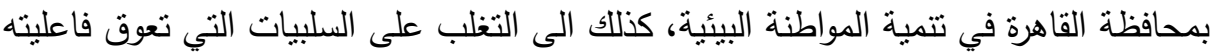

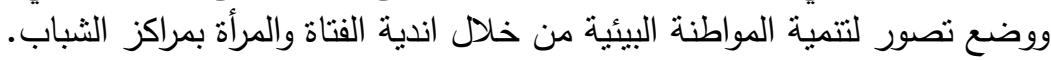

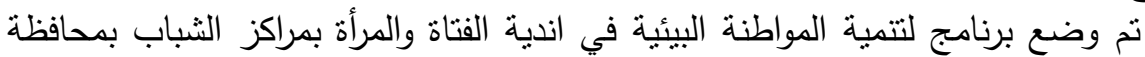

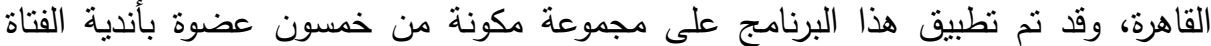

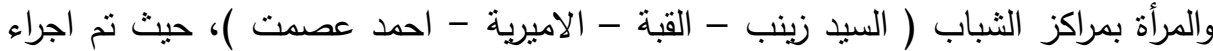
تطبيق لمقياس المواطنة البيئية المكون من اربعة ابعاد اساسية (مفهوم المواطنة البيئية -

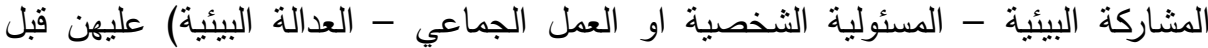
تطبيق البرنامج المقترح ثم اعبد تطبيق مقياس المواطنة البيئية عليهن بعد الانتهاء من نطبيق الئيق

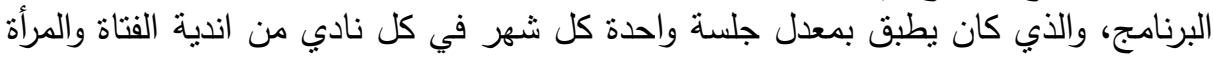

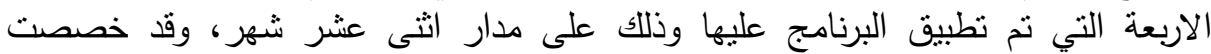

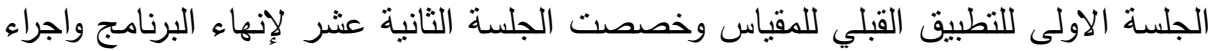

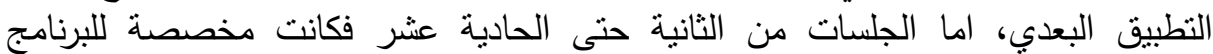

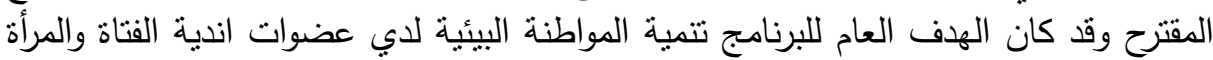

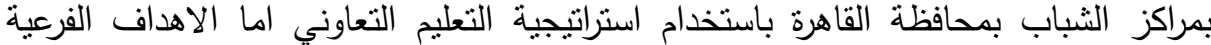

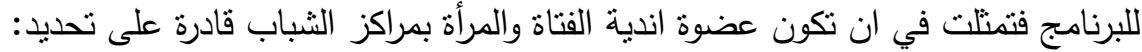
مفهوم المواطنة البيئية - ابعاد المواطنة البيئية - المشاركة البيئية - العينة العدالة البيئية المسئولية الثخصية نحو البيئة - العمل ضمن فريق لحماية البيئة

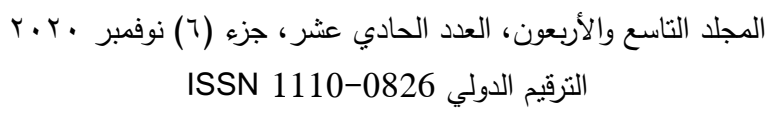


وقد راعى الباحثون عند اعداد البرنامج ما يلي: ابعاد المواطنة البيئية - خصائص المرحلة

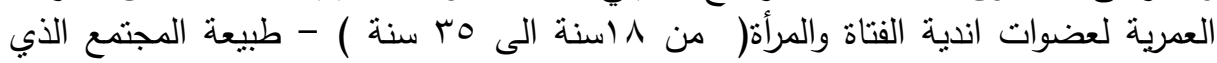
سوف يطبق فيه البرنامج.

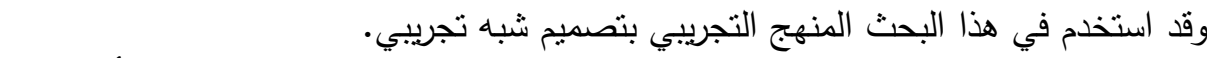

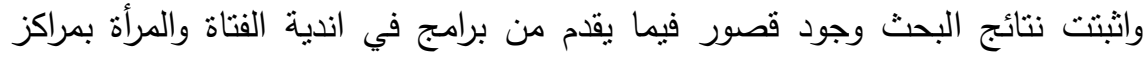

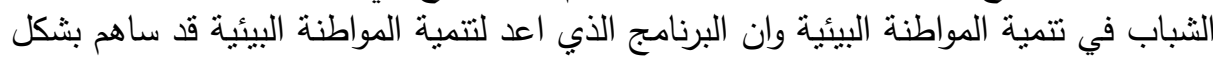

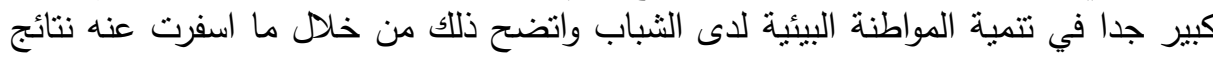
البحث بعد تطبيق البرنامج المقترح، حيث وجدت ولثية وفروق دالة احصائيا في المواطنة البيئية

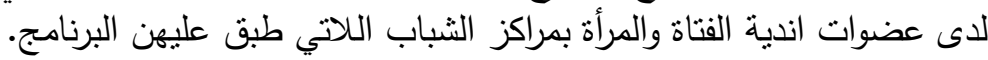
وقد اوصى البحث بما يلي: البئ ا ـ تطبيق برنامج تتمية المواطنة البيئية بكافة اندية الفتاة والمرأة بمراكز الثباب.

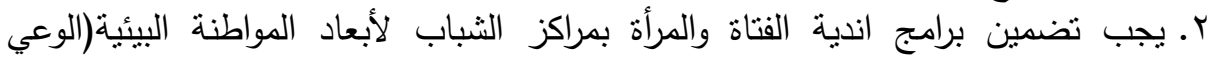

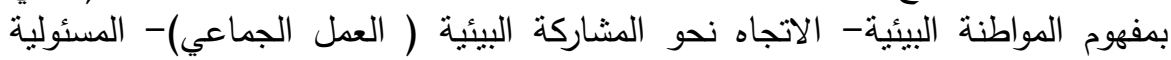

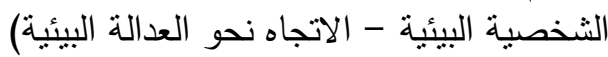

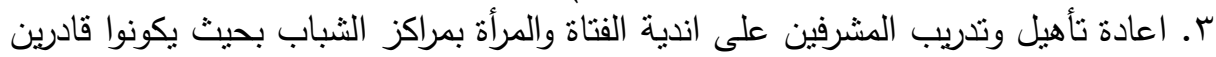

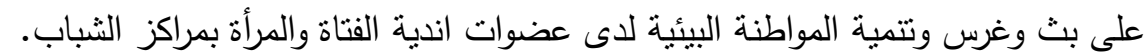

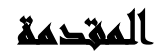

تحاول المجتمعات الانسانية بمختلف توجهاتها استثمار طاقاتها وامكانياتها ومواردها البشرية والمادية من اجل الوصول الى اقصى استفادة ممكنة من هذه الموارد ولا يوجد افضل بهل من الاستثمار في البشر للوصول الى تحقيق هذه الاهداف ومن هذا المنطلق كان الاهتمام

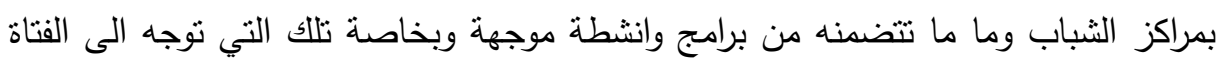

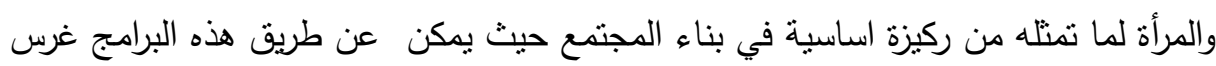

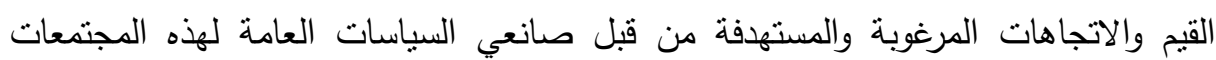
والتي من ابرزها قيمة المواطنة البيئية والتي تركز على إيجاد رادع ذاتي ينبع من داخل دانل

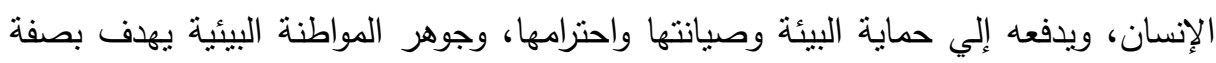
عامة إلي غرس مجموعة من القيم والمبادئ والمثل لدى أفراد المجتمع صغاراً كانوا أم كباراً، 238

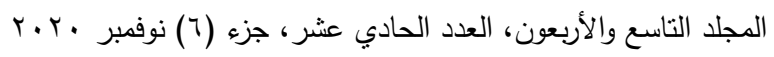

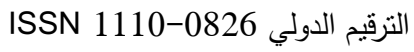


لتساعدهم في أن يكونوا صالحين وقادرين على المشاركة الفعالة والنشطة في كافة قضايا

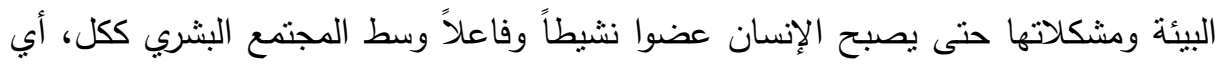

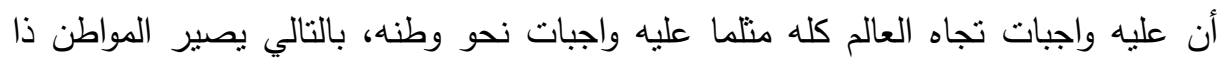

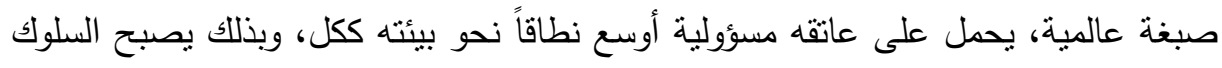
البيئي الصحيح ضرورة وجودية لبقاء الإنسان وليس مجرد رغبة أو شعار ، له أن يختاره أو أولئه

يرفضه.

تتحدد قوة المرأة في ممارسة المواطنة البيئية من خلال:

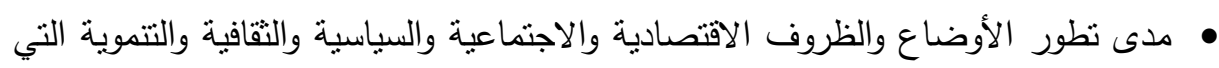
تنتبناها الدولة.

الحركة المنظمة لزيادة الفرص المتاحة للمرأة ومشاركتها الإيجابية الفعالة وتحقيق المساواة

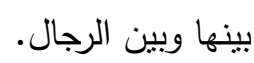
• كما تسعى المواطنة البيئية ذات الصبغة العالمية إلى تحقيق ما يلي: • إكساب المواطنين كافة المهارات اللازمة التي تساهم بشكلٍ فعال في الإصلاح البيئي و تحقيق التتمية المستدامة. تحسين السلوك البيئي اليومي للمواطنين، بما يعزز صحة البيئة وحمايتها من كافة أثنكال التلوث. هماية البيئة من مخاطر المشاريع التتموية التي قد تلحق الضرر بها، والمطالبة بضمان

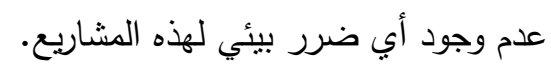
الإسهام في رفع مستوى المعرفة والثقافة البيئية بين عامة الناس، وتشجيعهم على المشاركة الفعالة في اتخاذ القرارات ووضع الحلول المناسبة للمشكلات البيئية ذات الأولوية. تبادل المعارف والخبرات بين الجهات الحكومية وغير الحكومية المعنية بقضايا البيئة والمشكلات البيئية ذات الأهمية .

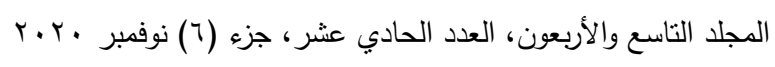

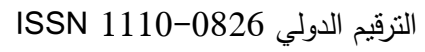


والمواطنة البيئية تعني المشاركة الفعالة للمواطنين في التوجه نحو الاستدامة، وهي

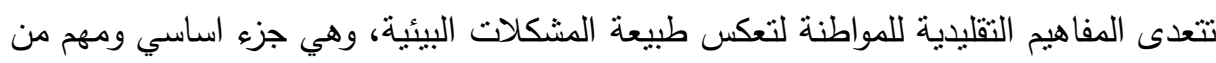

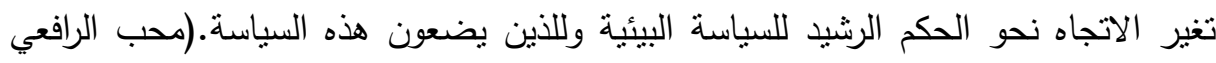
$((r \ldots \Lambda)$ ومن العوامل التي نساعد على تكوين المواطنة البيئية: 1-تفعيل القضايا البيئية وإعطائها الأولوية ضمن خطط النياعن التمية الثشاملة في الدولة واهتمام

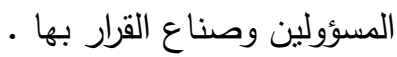
r-تعزيز القوانين والتشريعات البيئية التي يستتد إليها المواطنون من أجل تحقيق المواطنة البيئية. r-تعزيز الوعي البيئي من خلال برامج متخصصة يتم إعدادها وتتفيذها من قبل الجهات المعنية بقضايا البيئة ذات الأهمية. ع-دعم الجمعيات الأهلية البيئية وزيادة عددها ومشاركتها الفعالة في رسم الخطط والسياسات البيئية وتتفيذها وتقيمها. ه- إعطاء القضايا البيئية الأهمية الكافية ضمن أنظمة التعليم المختلفة وتتسيق جهودها بهدف

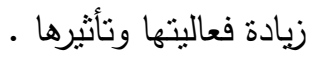
7-توظيف جهود الجمعيات الأهلية البيئية وتتسيقها، والاستفادة من المنظمات الدولية في دعم هذه الجمعيات فنباً ومادياً. V- التعاون مع المنظمات الثعبية وتحقيق التكامل فيما بينها نظراً لدورها الكبير في العمل البيئي. ^- التأكيد على إثراك كافة الجهات المعنية في وضع السياسات والاستراتيجيات والخطط وبرامج العمل البيئية وتقويمها ـ البرك

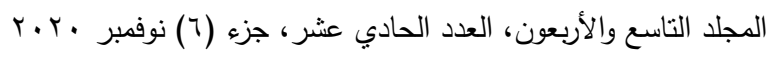

$$
\begin{aligned}
& \text { التزقيم الدولي 0826-0 }
\end{aligned}
$$


وتتمثل أسس بناء المواطنة البيئية من خلال تحديد الأهداف الرئيسة لتحقيق برامج ومشاريع المواطنة البيئية التي تتمنل في الآتي:

• تصحيح المفاهيم البيئية السائدة لدى المواطنين وبخاصة الفئه فئاة والمراة وتعديل المعتقدات والأفكار البيئية الخاطئة، ومعالجة أساس المشاكل للسلوكيات السلبية الناجمة عن غياب مفهوم المواطنة البيئية لديهن. إكساب الفتاة والمرأة المهارات والآليات السليمة والمفيدة والصحيحة التي نساهم في المحافظة على البيئة والإصلاح البيئي من أجل التتمية المستدامة.

• تحسين السلوك البيئي لدى الفتاة والمرأة المتبع في الحياة العامة أثناء التعامل مع البيئة. ه السعي إلى تجنب الأضرار البيئية قبل نشوئها والمطالبة بإثبات عدم وجود أضرار بعيدة المدى للأنشطة البيئية المقترحة. الإسهام في رفع مستوى المعرفة والتقافة البيئية العامة للفتاة والمرأة لتحفيزهن على التهائ المشاركة في اتخاذ القرارات ووضع الحلول المعنية بالثنؤون البيئية والتتموية. • تبادل الخبرات بين المنظمات الحكومية وغير الحكومية.

كيف تتحقق المواطنة البيئية؟

إن تحقيق ذلك مرتبط بوجود الوسائل العملية والمنمنلة في ضرورة وجود الحركة البيئية الفاعلة في مواجهة سياسات همجية الحضارة وسياسات التدمير البيئي، ووجود الثراكة الواعية والتعاون الدولي الموجّه في أهدافه لتنخيص وإيجاد قواعد نظام دولي ديمقراطي وعادل في حل المشكلات الدولية، يعترف بشكل فعلي بتتوع الثقافات وتعدد الحضارات، ويجسّد المنهج الواقعي في التعاطي مع حقوق مختلف الجماعات البشرية في السيادة على مصادر ثرواتها

وكنلك وجود المؤسسات البرلمانية التي تدعم الخطط والجهود الاجتماعية في إقرار

الحقوق البيئية وجعلها واقعاً ملموساً في سياسات الدول، إلى جانب وجود المؤسسات والإدارات

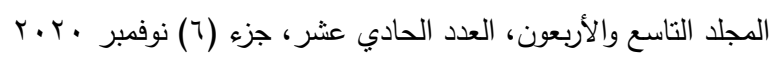


البيئية والرقابية التي ترنكز في عملها على القواعد والأنظمة والمقاييس والمعايير البيئية

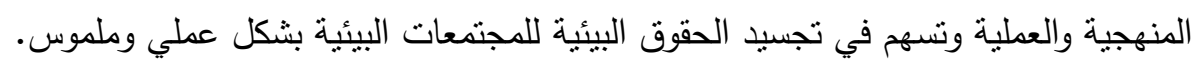

\section{And}

من خلال عمل الباحثون في متابعة انشطة وبرامج مراكز الثباب وبخاصة برنامج اندية الفتاة والمرأة، وما قاموا به من تحليل محتوى ومضمون للبرنامج المستخدم في اندية الفتاة

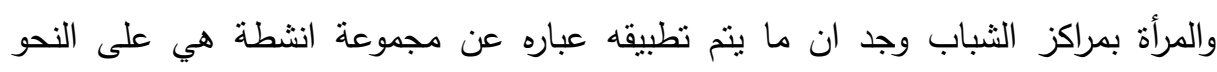

$$
\text { • ورشة فنية لتتمية المهارات لخامات البيئة. }
$$$$
\text { • ن ندوة توعية عن التتشئة الصحية للأسرة. }
$$$$
\text { • • • ورشة فنية لأعمال بوكيه الورد والاشجار . }
$$$$
\text { • ورشة تدريب على حرفة الخيامية. }
$$$$
\text { • • ورشة تدريب على صناعات الجلود. }
$$

• ورشة فنية لتتمية المهارات اليدوية لخامات البيئة.

$$
\text { • • ورشة فنية في مشغولات الورود. }
$$$$
\text { ندوة توعية عن التشئة الصحية. }
$$

وهذه الانشطة لا تساعد على تتمية المواطنة البيئية في حد ذاتها على الرغم من ان

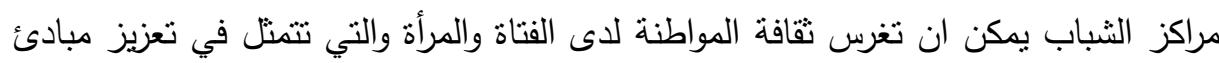

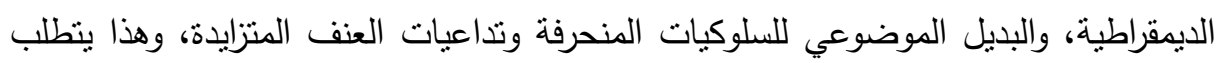
مراجعة تلك المراكز لأهدافها التربوية، واستحداث آليات جديدة للتفعيل الحقيقي لقيم المواطنة

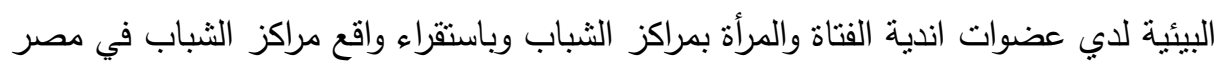

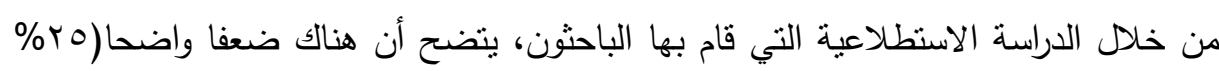

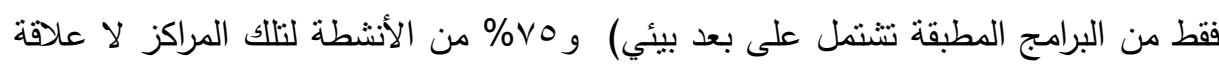
242

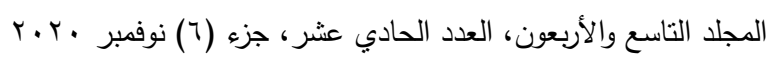

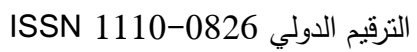




$$
\begin{aligned}
& \text { مجلة العلوم البيئية } \\
& \text { معهد الدراسات والبحوث البيئية - جامعة عين شمس له } \\
& \text { ياسر علي محمد وآخرون }
\end{aligned}
$$

لها بالبيئة وبصفة خاصة قيمة المواطنة البيئية بين الثباب عموما والفتاة والمرأة على

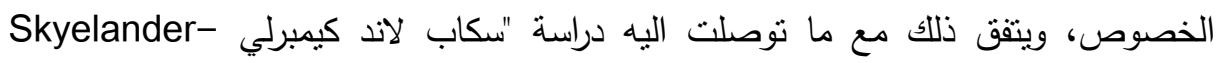
Kimberly, • وصف برامج المواطنة البيئية التي تستخدم مع الكبار في مراكز التربية البيئية. • كيفية تتفيذ هذه البرامج بالمفوضية الاوربية للبالغين.

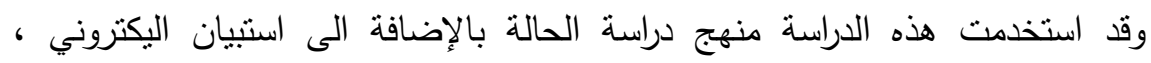
واعتمدت في تتفيذ برنامجها على الرحلات الميدانية وورش العمل. وقد خلصت نتائج دراسة "سكاب لاند كيمبرلي Skyelander-Kimberly الى لئ وجود

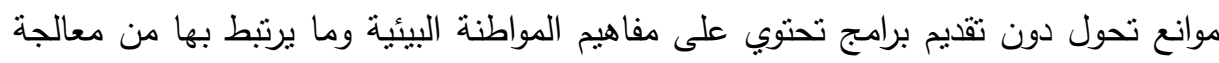

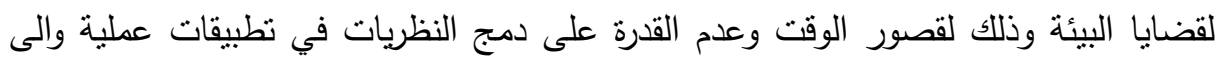
احنياج القائمين على برامج تتمية المواطنة الى مزيد من التدريب. (- 2004)-pg,143, (Skyelander-Kimberly وتتفق دراسة "سكاب لاند كيمبرلي Skyelander-Kimberly مع ما لاحظه الباحثون في اندية الفتاة والمرأة بمراكز الثباب بمحافظة القاهرة من قصور في تحقيق الأدوار التربوية

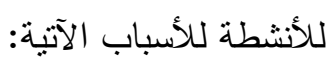

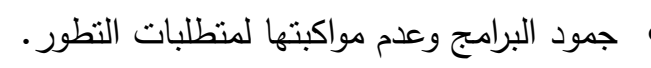

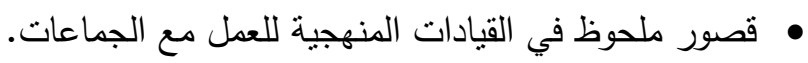

• قصور الوعي بالدور التربوي الذي تقوم به مراكز الثباب من خلال أنثطتها المختلفة.

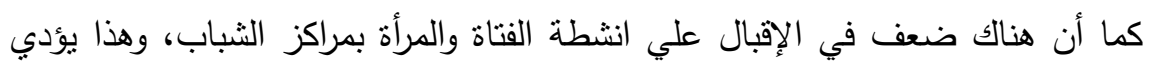

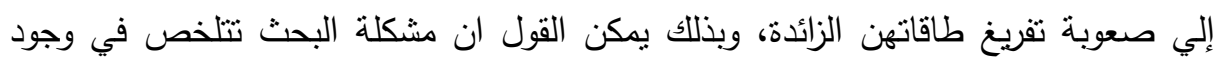
قصور في البرنامج المطبق في اندية الفتاة والمرأة بمراز الثباب حيث لان لانئ يعمل هذا البرنامج على تتمية المواطنة البيئية.

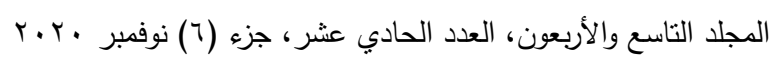

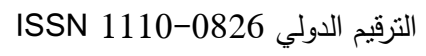




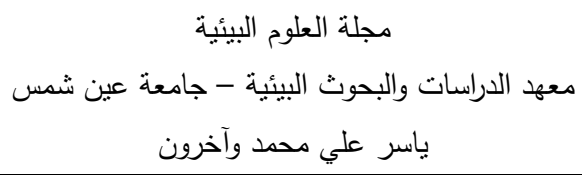

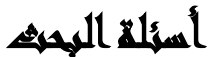

في محاولة للتصدي لهذه المشكلة سيحاول البحث الإجابة علي السؤال الرئيسي الآتي: "ما فاعلية برنامج مقترح قائم على التعليم الاجتماعي او التعليم بالنمذجة في اندية

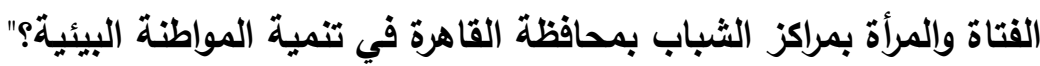
ويتفرع من هذا السؤال الاسئلة الفرعية التالية: - ما الابعاد التي يجب التركيز عليها في برامج أندية الفتاة والمرأة بمراكز الثباب بمحافظة القاهرة لتتمية المواطنة البيئية؟ - الى اي مدى تتوافر هذه الابعاد في البرامج الحالية المطبقة في أندية الفتاة والمرأة بمراكز

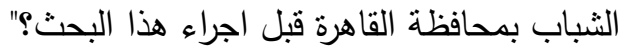
- ما البرنامج المقترح لأبعاد المواطنة البيئية التي يجب تنميتهاء لئها بيرامج أندية الفتاة والمرأة بمراكز الثباب بمحافظة القاهرة؟ - ما فاعلية البرنامج المقترح من تتمية المواطنة البيئية بأندية الفتاة والمرأة بمراكز الثباب

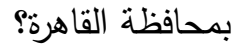

\section{And llats}

التزم البحث الحالي بالحدود الاتية: الحدود الزمنية: تم اجراء هذا البحث على مدار عامي من اول يناير 9 اــآم حتى نهاية ديسمبر 19 19 إم الحدود البشرية: نم تطبيق البحث على عينة مكونة من خمسون عضوة بأندية الفتاة والمرأة بمراكز الثباب بمحافظة القاهرة. الحدود المكانية: نم تطبيق البحث على أربعة اندية من اندية الفتاة والمرأة بمراكز الثباب

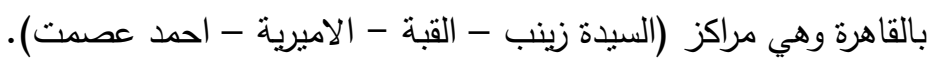

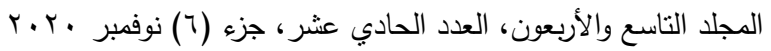

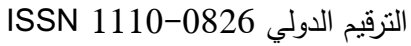




\section{أهمية الهمهي}

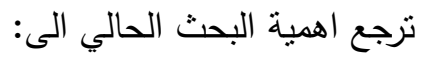

الأهمية التطبيقية: قد يستقيد من البحث الحالي مخططي البرامج الخاصة بأندية الفتاة والمرأة بمراكز الثباب. اعضاء مراكز الثباب من الجنسين. المشرفون على برامج تتمية المواطنة البيئية بمراكز الثباب. تحويل المفاهيم النظرية للمواطنة البيئية الى سلوكيات حياتية.

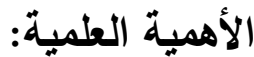

ان هذا البحث يقدم قائمة بأبعاد المواطنة البيئية. كما يقدم مقياس للمواطنة البيئية قد يفيد الباحثين في مجالات لهدئ عديدة. كما يقدم برنامج لنتمية المواطنة البيئية لدى الفتاة والمرأة.

\section{أهمانها المهنه.}

يهدف البحث الحالي الي تتمية المواطنة البيئية لدي أعضاء أندية الفتاة والمرأة بمراكز شباب محافظة القاهرة من خلال البرنامج الذي اعده الباحثون.

$$
\text { منهج البحث: اعنمد البحث علي المنهج التجريبي. }
$$

المنهج التجريبي: حيث تم الاعتماد علي التصميم شبه التجريبي للمجموعة التجريبية الواحدة (القبلي - البعدي) حيث سيتم قباس المواطنة البيئية قبل وبعد تطبيق البرنامج المقترح لقياس أثز المتغير المستقل (البرنامج المقترح) علي المتغير التابع للمواطنة البيئية. أدوات البحث: تمثلت أدوات البحث التي قام الباحثون بإعدادها فيما يلي: قائمة بأبعاد المواطنة البيئية كما ينبغي ان تكون بأندية الفتاة والمرأة بمراكز الثباب. لبابل مقياس المواطنة البيئية من اعداد الباحثون. بادن.

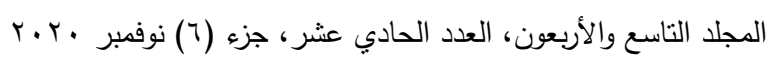


برنامج تتمية المواطنة البيئية من اعداد الباحثون.

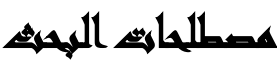

ومن اهم المصطلحات التي استخدمت في هذا البحث(فاعلية - البرنامج - المواطنة

البيئية).

الفاعلية: قد تتداخل مفاهيم الفعالية مع الكفاءة ومع النجاح؛ فمن حيث المبدأ يمكن استخدام النعت "فعّال" بشكل كمّي، ويمكن القياس والمقارنة بالقول أن عملية ما كانت فعّالة بشكل جيد جداً أو فعالة بشكل أقل، في حين أن النجاح تعطي دلالة على الحد الذي وصل إليه الألثر

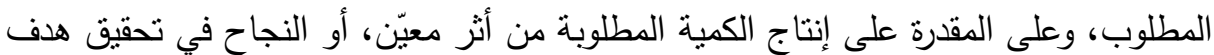
معيّن وذلك بغض النظر عن الموارد والجهد المبذول لتحقيق ذلك الهدف، وهنا يختلف مفهوم النجاح عن مفهوم كفاءة، إذ أنه في الأخير تؤخذ نلك العوامل الاقتصادية بعين الاعتبار . يقصد بالفاعلية في هذا البحث كفاءه البرنامج الذي اعده الباحثون في تحقيق تنمية

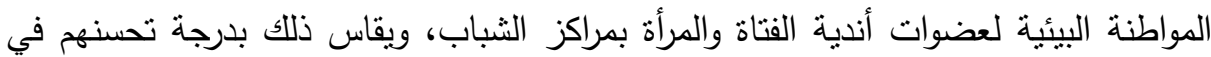

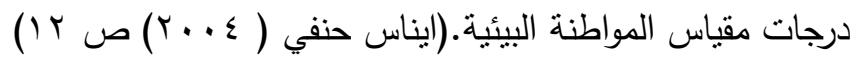
البرنامج: هو المخطط العام الذي يوضع في وقت سابق على عمليتي التعليم والتدريس في مرحلة من مراحل التعليم، ويلخص الاجراءات والموضوعات التي تتظمها المدرسة خلال مدة معينة كما يتضمن البرامج والخبرات التعليمية التي يجب اندراءت ولكتسبها المتعلم.(اللقاني والجمل

$$
(\vee \leq ص(r \ldots r)
$$

يقصد بالبرنامج في هذا البحث مجموعة من الأنشطة والعمليات المقصودة التي يمكن

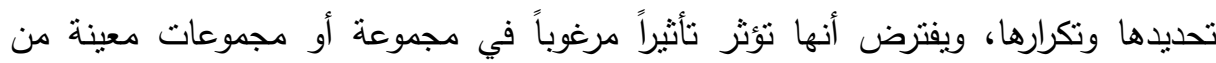

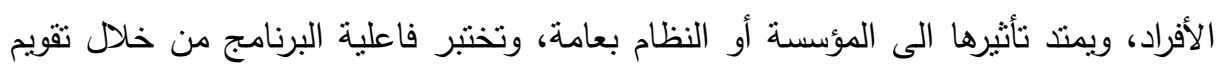

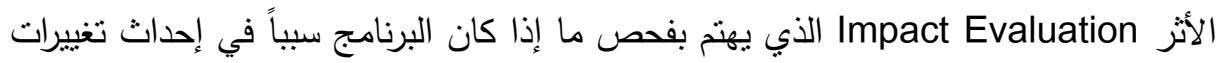

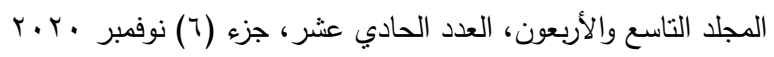

$$
\begin{aligned}
& \text { الترقيم الدولي 0826-1110 }
\end{aligned}
$$


في الاتجاه المطلوب، وهذا يتطلب نوضيح الأهداف الإجرائية له، وتحديد محكات النجاح، وقياس التقدم نحو الأهداف.

المواطنة البيئية (Environmental Citizenship):

تعني المواطنة البيئية أن يكون المواطن متحمساً وواعياً للقضايا البيئية ذات الأهمية،

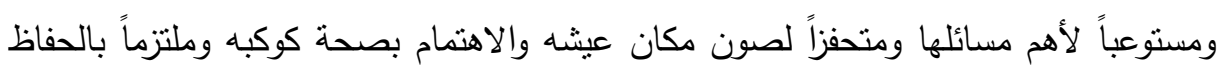

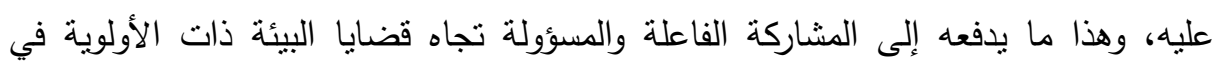
مجتمعه لرد كافة التحديات التي تواجه أجيال الحاضر وأجيال المستقبل. وهي اسلوب للحياة تفرضه الواجبات الاخلاقية التي تربط بين البشر في مختلف جهات العالم، بخصوص البيئة وما يتصل بحمايتها وحسن استغلال مواردها بطريقة مستدامة، وذلك على مستويات متعددة ومتدرجة، بداً من بيئة الاسرة والمجتمع المحلي، وانتهاءً بحماية بيئة

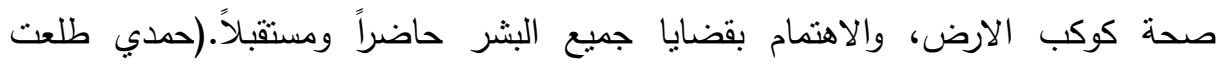

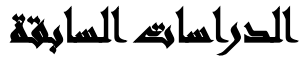

دراسة محمد العجوز(؟ 99 (م)): وهي بعنوان "دور مراكز الثباب في تنمية الوعي

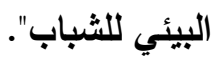

وهدفت هذه الدراسة الي التعرف علي دور مراكز الثباب في تتمية الوعي البيئي لدي

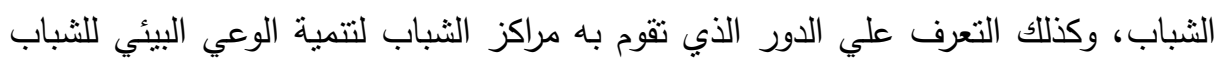

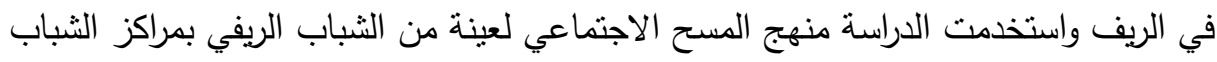

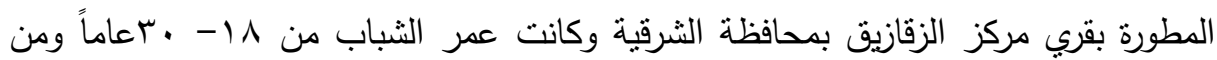
أهم ادوات الدراسة اعداد مقياس لقياس الوعي البيئي للثباب الريفي تم تطبيقها علي الثباب المشتركين في مراكز الثباب وقد نوصلت الدراسة الي أهم النتائج ومنها: 
ان القيادات المتخصصين ذات الكفاءة تعتبر عنصر جذب للأعضاء وانتظام العضوية

وكثافة التردد وتطور البرامج بما يتفق وتحقيق الهدف وبما يتتاسب مع ميول الأعضاء.

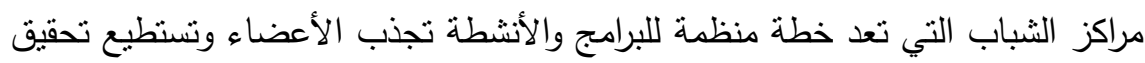

بالإضافة الي وجود فروق بين الذكور والاناث في مسنوي الوعي البيئي.(محد محمد

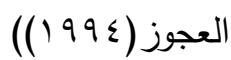

دراسة (مصطفي قاسم • 1 • r م): وهي بعنوان إسهام مراكز الثباب في تدعيم قيم المواطنة لاى الثباب". وهدفت هذه الدراسة الي معرفة اسهامات مراكز الثباب في تدعيم وتتمية المواطنة لدي الثباب من خلال البرامج الرياضة والاجتماعية والثقافية والرياضة، وتتتمي الدراسة الي الدراسات الوصفية واستخدمت المنهج الوصفي علي عينة من الثباب، وقد توصلت الدراسة

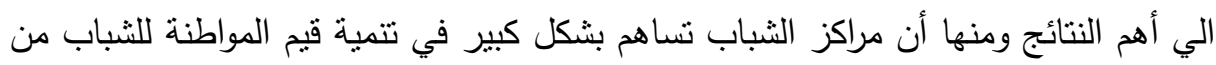

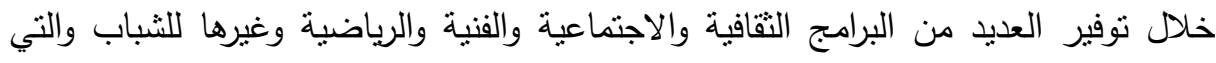

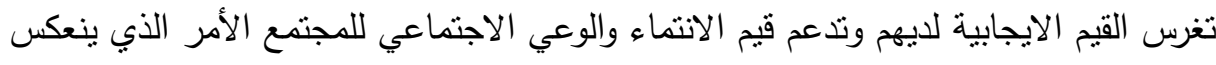

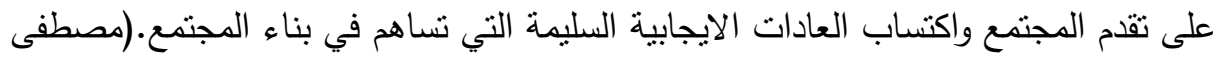

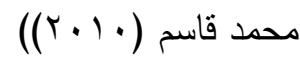
دراسة (هبه يحيي • 1 • r م): وهي بعنوان "مسئولية المؤسسات الثبابية في تفعيل دور الفتيات نحو البيئة". وهدفت هذه الدراسة الي التعرف علي دور مسئولية مراكز الثباب في تتمية الوعي البيئي

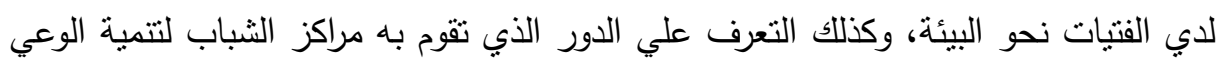
البيئي للفتيات واستخدمت الدراسة منهج المسح الاجنماعي لعينة من الفتيات المشتركات بمراكز الثباب ومن هذه الدراسة يتضح أنه مازالت هناك ثقافة راسخة نحو تهميش دور الفتاة

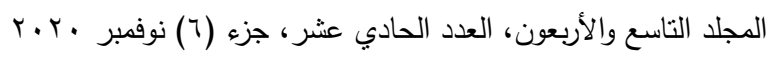

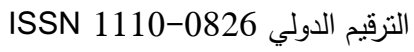


من أسر الفتيات وان ميل الفتيات الصغيرات أكبر نحو الأنشطة الرياضية والترفيهية لذا يجب

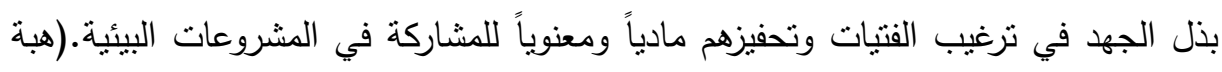

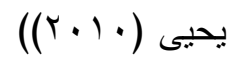

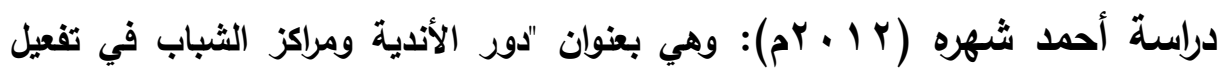
المشاركة المجتمعية لاي الشباب".

وهدفت هذه الدراسة الى رفع وعي الثباب وتعريفهم علي الششكلات البيئية لتحفيز

الثباب والمرأة علي العمل التطوعي في مجال البيئة، وتسنطيع القول بأنه مع تقديم الخدمات

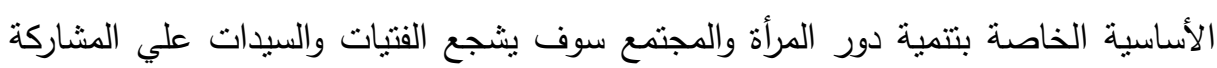
في الندوات النتقيفية والتدريبية علي بعض الحرف من خلال عمل معارض للمنتجات الاسرية وتسويقها مما بساعد علي رفع المستوي المعيشي وبالتالي رفع المستوي الثقافي والوعي البيئي

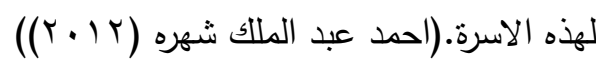
دراسة بيتر سون دونا (Peterson Donna 2005). وهدفت هذه الدراسة الي التعرف على طريقة التأثير في الطلاب خارج المدرسة والعلاقة بين المجتمع والجامعة لتطوير الأخلاق

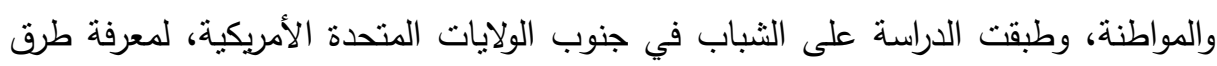

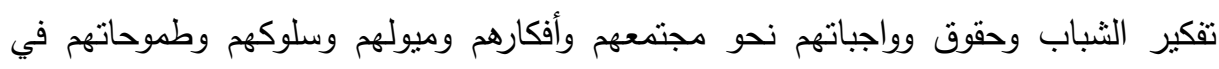

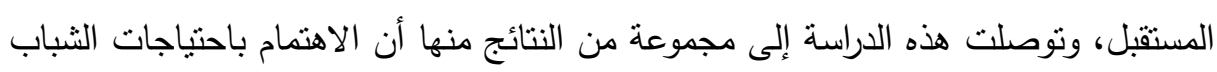
وتتمية المعارف العلمية لديهم وتحقيق التعاون بين الجامعة ومؤسسات المجتمع ومساعدة

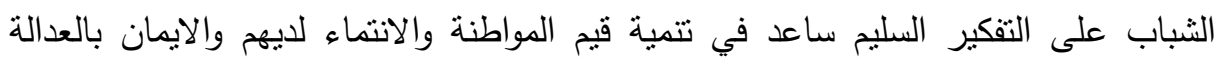

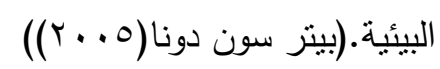
دراسة ولكر جيوس (Walker Joyce2005). والتي استهدفت التعرف على صور المواطنة بين الثباب ودور المعلمين في الجامعة ومعاهد التعليم في إكساب هؤلاء الثباب قيم

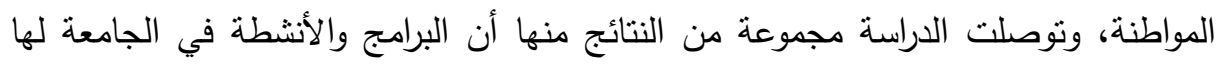

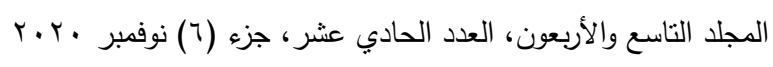


علاقة وتأثير إيجابي في مساعدة الثباب على اتخاذ القرار والإدراك الصحيح لاحتياجاته

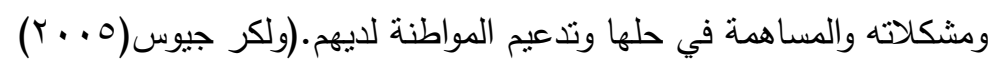
دراسة ماجيك هنري (Magick Hanray2007): والتي تهدف إلى التعرف على تأثير الجامعة في تعليم الطلاب حقوق وواجبات المواطنة وأدوارهم في المجتمع، وقد نوصلت الدراسة

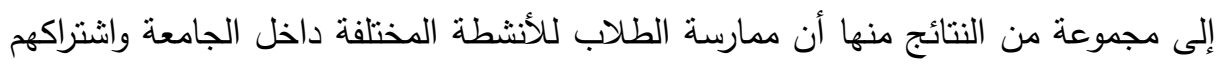
في الحوارات والمناقثات مع المعلمين واثشتراكهم في قضايا ومشكلات المجتمع وفهم

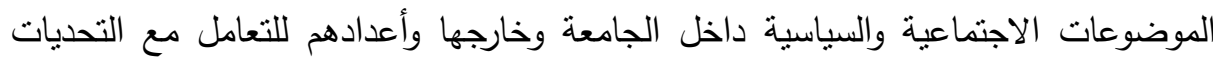

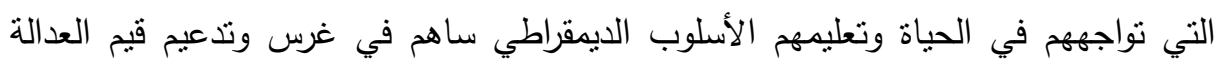

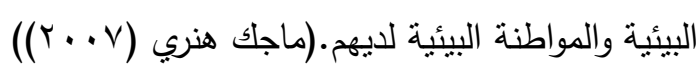
دراسة حسام طلعت (11 + ب م):

استهدفت الدراسة التعرف علي دور مراكز الثباب في إكساب المرأة المصرية قيمة

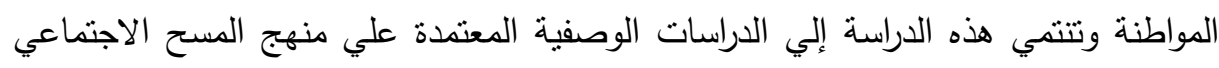
بالعينة، واعتمدت الدراسة علي أداة رئيسية وهي مقياس دور مراكز الثباب في تلتمية قيمة الثية المواطنة لدي المرأة المصرية وطبقت الدراسة علي مركز شباب مدينة المحلة الكبرى بمحافظة

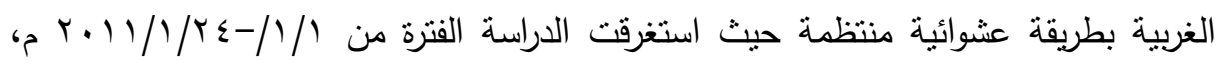
وتوصلت الدراسة إلي إن الغالبية العظمي من عينة الدراسة الذين يتراوح عضويتهم بالمركز ما

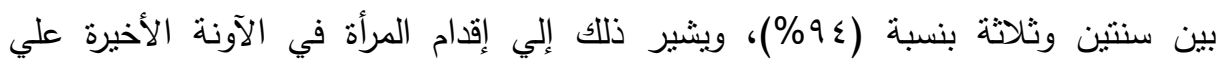
المشاركة في العمل السياسي. دراسة حمدي طلعت(11 +rrم). كان الهدف من هذه الدراسة معرفة أوجه القصور في البرامج والمناهج الدراسية في تتمية المواطنة البيئية والتعرف علي الوضع الحالي للمواطنة

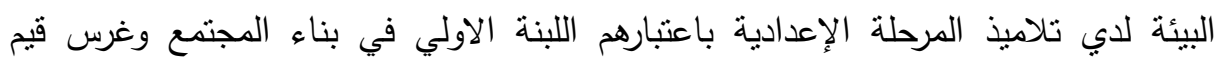
المواطنة البيئية في سلوكهم. وقد خلصت الدراسة الي النتائج الاتية: ان التعليم التقليدي لإئي

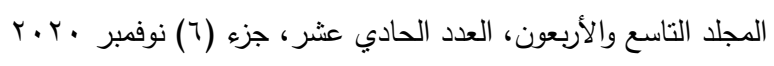

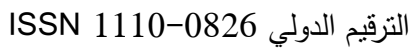


المعتمد علي التلقين لا يخلق الوعي بأهمية المواطنة وأنه يجب التركيز وبدرجة أساسية علي الأنشطة التي تساعد التلاميذ علي تتمية المواطنة البيئية. وان نشر الوعي بالحقوق والواجبات البيئية بين تلاميذ المدارس من خلال ومع معائه مسابقات ورحلات تتاقش موضوعات وقضايا البيئية محلياً وعالمياً ينمي عندهم مفهوم المواطنة البيئية، بالإضافة الي خلق بيئة جاذبة لممارسة المواطنة من خلال التعلم التعاوني. الموجهات النظرية للبحث: يعتمد الباحثون في تفسير نتائج هذا البحث على نظرية التعليم بالنمذجة ( نظرية التعليم الاجتماعي)

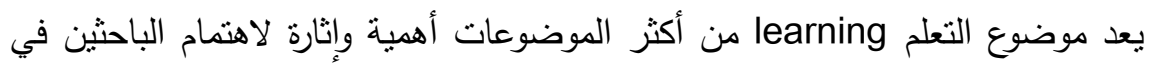
مختلف التخصصات وذللك للتعرف على هذه الظاهرة الإنسانية المعقدة من خلال التوصل إلى الى لفي قوانين تتحكم بها، بما بسهم في استثمارها وتوظيفها في المواقف الحياتية المختلفة وخاصة التهنة التربوية والاجتماعية منها. فأهمية التعلم تكمن في كونه عملية يكتسب فيها الفرد أنماطاً سلوكية جديدة ومهارات

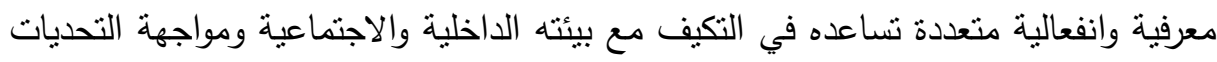
والمخاطر المحيطة به، ولقد ظهرت العديد من نظريات التعلم التي تهدف لتقديم فهم أفضل وأعمق للسلوك الإنساني. ونظرية التعلم الاجتماعي أو التعلم بالنمذجة تؤكد على أهمية التفاعل الاجتماعي،

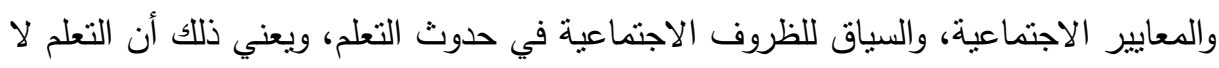

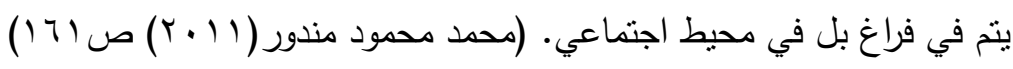
ويقصد بالتعلم الاجتماعي : كتساب الفرد أو تعلمه لاستجابات أو أنماط سلوكية جديدة

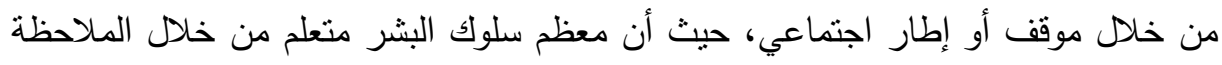
سواء بالصدفة أو بالقصد. فالطفل الصغير يتعلم الحديث باسنماعه لكلام الآخرين وتقليدهم.

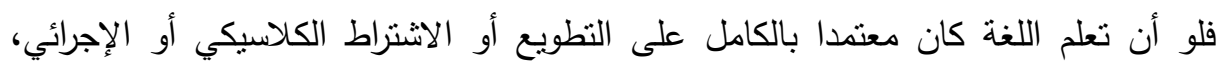

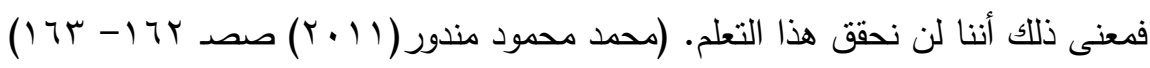

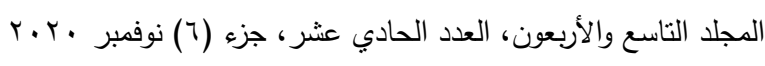


ويقصد بالتعلم بالملاحظة observational learning فهو التعلم الذي يحدث من خلال ملاحظة سلوك الآخرين. فالتعلم بالملاحظة بترك آثناراً متتوعة على سلوك الإنسان

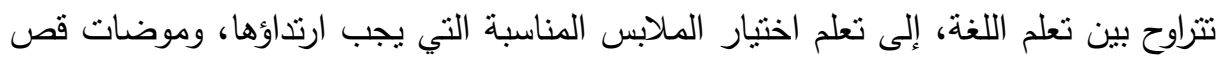
الثعر لمراع كما يطلق ألبرت باندورا (مؤسس النظرية) على التعلم بالملاحظة -والذي يحدث عندما

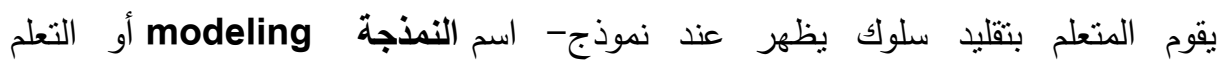

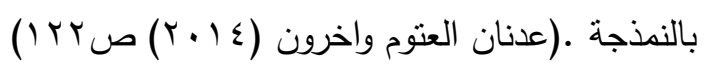

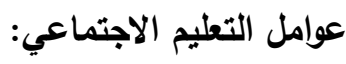
- عوامل متعلقة بالفرد الملاحِظ ومنها (العمر الزمني والاستعداد العقلي، تقديره للمكانة العلمية والاجتماعية للنموذج والجاذبية الثخصية والارتياح النفسي للنموذج). - عوامل متعلقة بالنموذج الملاحَظ ومنها (المكانة الاجتماعية - الثهرة -النوع).

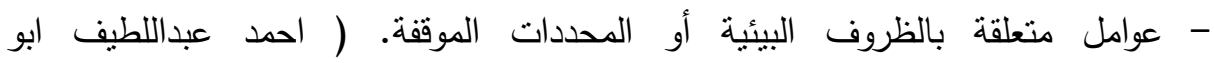

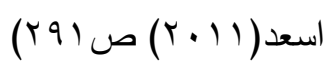
مصادر التعلم الاجتماعي: 
أولاً: التفاعل المباشر مع الأثخاص الحقيقيين في الحياة الواقعية: يمكن أن يتم تعلم العديد

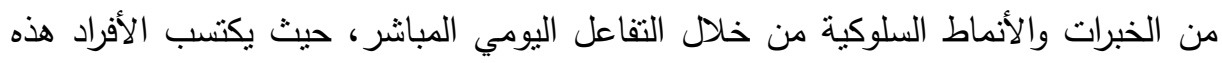

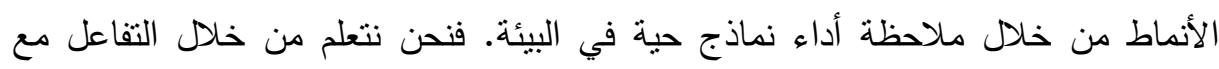

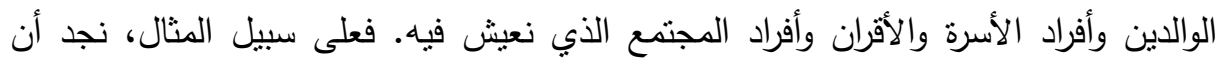

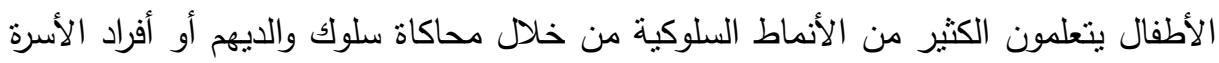

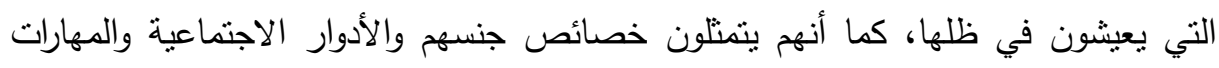

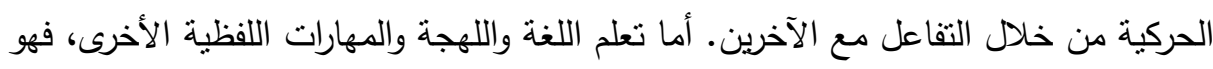

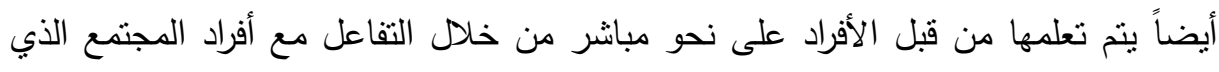
يعيشون فيه. ثانياً: التفاعل غير المباشر ويتمثل في وسائل الإعلام المختلفة: يمكن من خلال هذه

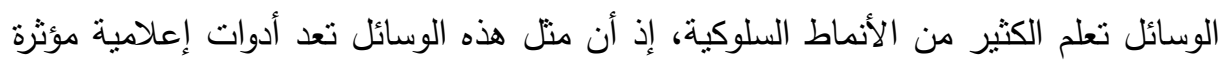

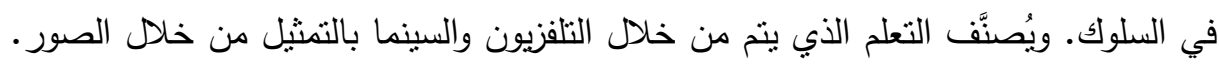

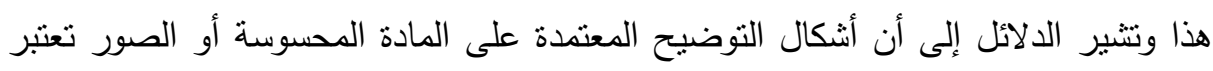

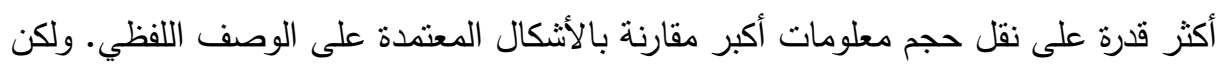

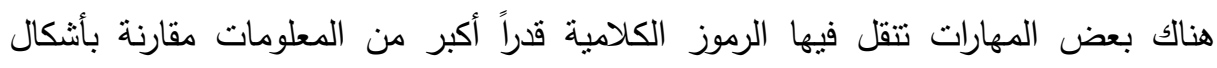
التمثيل بالمادة والصور كما هو الحال في تعلم اللغة واللهجة.

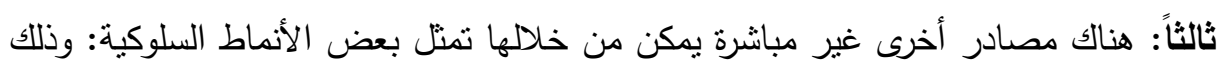

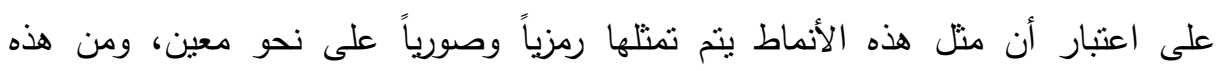

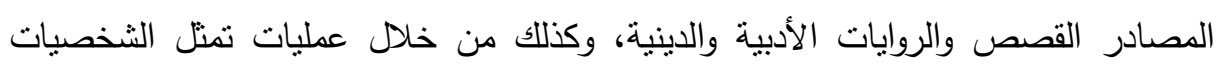

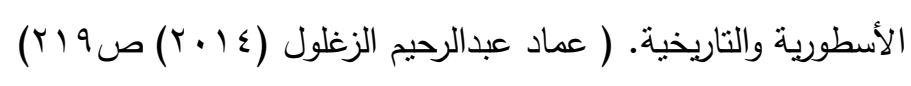

التطبيقات التربوية لنظرية التعلم بالنمذجة:

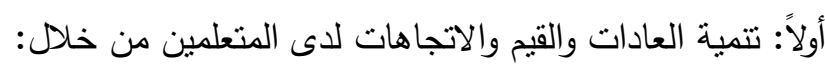
- أن يكون المعلم قدوة للمتعلمين بممارسة العادات والقيم.

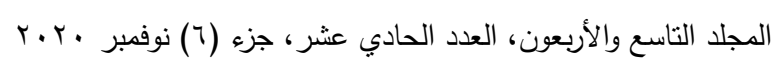

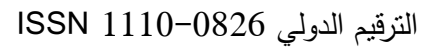


- استخدام نماذج من الطلبة ممن يمارسون مثل هذه العادات والقيم وتعزيزهم على ذلك أمام الطلبة الآخرين. - استخدام الأفلام التي نتنتمل مواد تتعلق بنلك القيم والعادات والاتجاهات. - استخدام القصص والروايات والسير الهادفة والتي تكفل توفير نماذج مثالية للمتعلمين. ثانياً: تتمية المهارات الرياضية والفنية والحرفية: والمتعلقة بتدريس المواد الأكاديمية من خلال وله

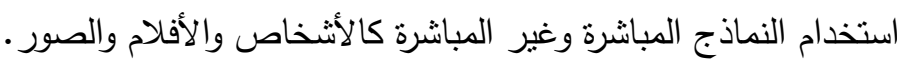

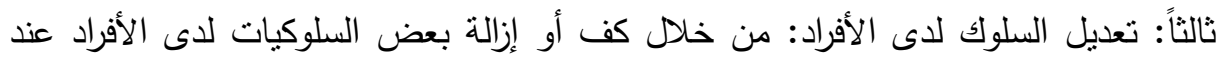

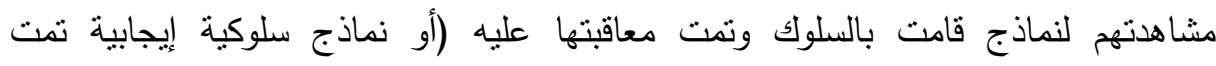

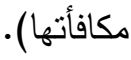
وقد بينت دراسات عديدة أن التلاميذ يتأثرون بسلوك معلميهم وتصرفاتهم أكثر من تأثرهم

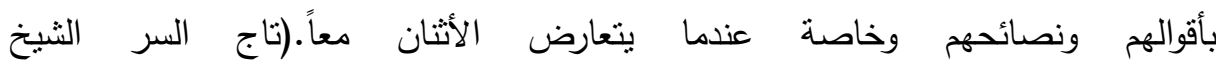

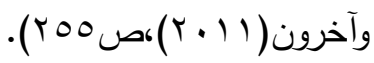

\section{إلجراءاهت المهيف}

للإجابة على السؤال الفرعي الاول" ما الابعاد التي يجب التركيز عليها في برامج أندية

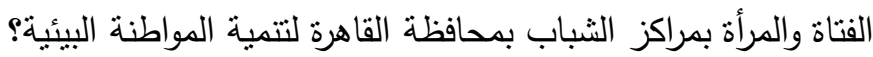
" قام الباحثون بتحديد الاهداف التي يجب ان تحققها برامج اندية الفتاة والمرأة لتتمية المواطنة البيئية وذلك من خلال ما توصلوا اليه من قصور في البرنامج المطبق قبل التناخل

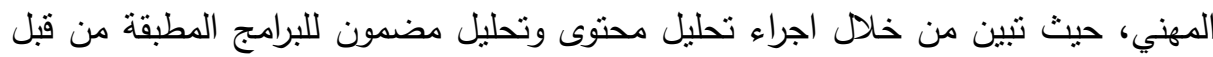

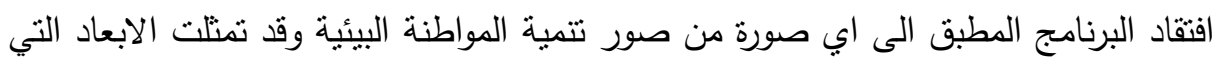

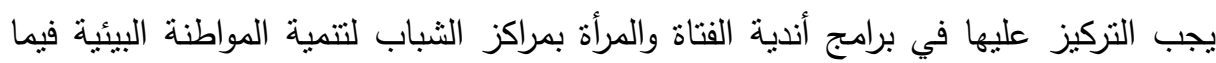

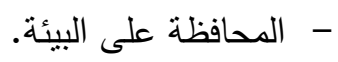

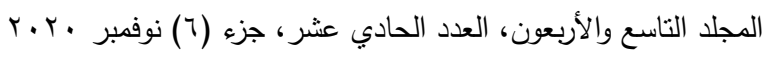

$$
\begin{aligned}
& \text { الترقيم الدولي 0826-1110 }
\end{aligned}
$$




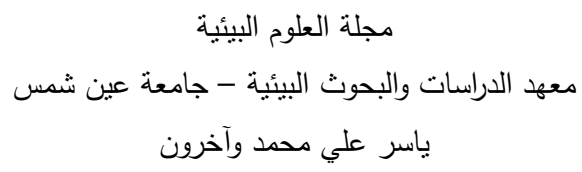


الاولى للنطبيق القبلي للمقياس وخصصت الجلسة الثانية عشر لإنهاء البرنامج واجراء التطبيق

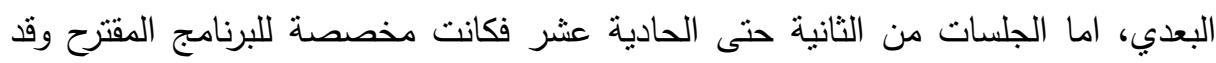
كان الهدف العام للبرنامج تتمية المواطنة البيئية لدي عضوات البئية الندية الفتاة والمرأة بمراكز الثباب بمحافظة القاهرة باستخدام استراتيجية التعليم التعاوني اما الاهداف الفرعية للبرنامج لهابه فتمثلت في ان تكون عضوة اندية الفتاة والمرأة بمراكز الثباب قادرة على تحديد: 1 ا ـ مفهوم المواطنة البيئية. r البعاد المواطنة البيئية.

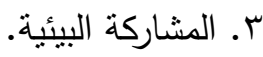

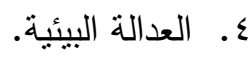
0. المسئولية الثخصية نحو البيئة. 7. العمل ضمن فريق لحماية البيئة وقد راعى الباحثون عند اعداد البرنامج ما يلي:

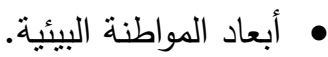

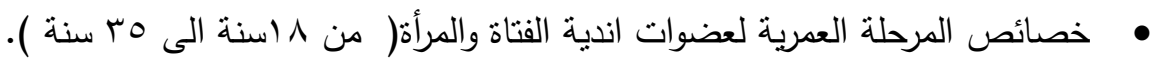
طبيعة المجتمع الذي سوف يطبق فيه البرنامج.

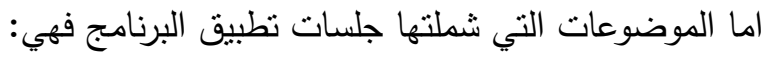
أ- بيئة امنة من التلوث داخل مركز الثباب. ب- اعداد مجلة حائط تشمل موضوعات بيئية. ج- عمل مناقثة جماعية عن مصادر الثلوث في محيط مركز الثباب. د- عرض لموارد البيئة المحيطة بالمركز • هـ - مناقثنة كيفية المحافظة على المرافق العامة. و - مناقنة جماعية عن نأثير الملوثات السمعية على الانسان. 
ز - كيفية الاستفادة من وسائل التواصل الاجتماعي والتكنولوجيا الحديثة في معالجة قضايا البيئة. ح- تذوبر النفايات واعادة استخدمها. ط- تصورات مقترحة لبيئية عالمية خالية من التلوث. ي- عادات وسلوكيات ضارة بالبيئة وكيفية التغلب عليها.

للإجابة على السؤال الفرعي الرابع" ما فاعلية البرنامج المقترح من تتمية المواطنة البيئية

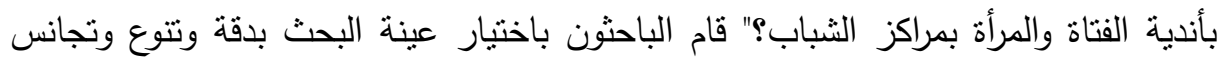

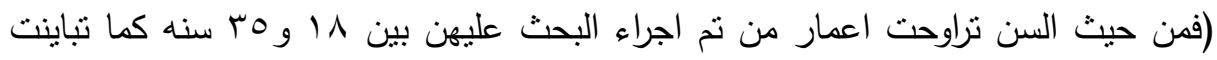

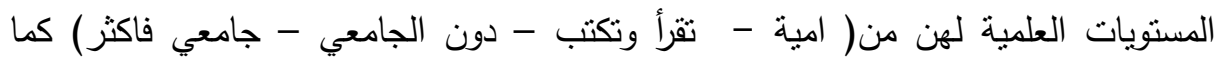
تباينت الحالة الاجتماعية لهن بين ( انسة - متزوجة - مطلقة - ارملة) ثم قاموا بأعداد مقياس المواطنة البيئية( والذي تم اعداده بمعرفة الباحثون والذي ينكون من خمسة محاور اساسية حيث يشمل المحور الاول المعلومات الاساسية عن المبحوث، ويشمل المحور الثاني العبارات التي تقيس مفهوم المواطنة وعددها ستة عشر عبارة، والمحور الثالث ويشمل العبارات التي تقيس المشاركة البيئية وعددها ثلاث عشر عبارة، والمحور الرابع ويشمل العبارات التي تقيس المسئولية الثخصية والعمل الجماعي وعددها ثلاث عشر عبارة، والمحور الخامس ويشمل العبارات التي تقبس العدالة البيئية وعددها ثمانية عثر عبارة، وقد تم عمل كافة الاجراءات العلمية والعملية اللازمة للتأكد من صدق وثبات المقياس قبل تطبيقه يقصد بالصدق ان يقيس المقياس فعلاً الظاهرة محل القياس وبعد استطلاع اراء المحكمين من العلماء والعاملين في المجال وللتأكد من مدى صلاحية المقياس قام الباحثون بإجراء اختبار للمقياس

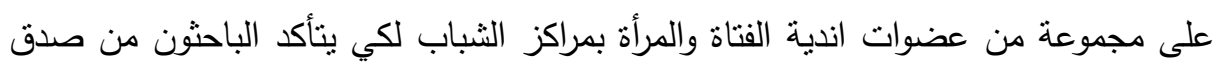
المقياس اتبع طريقة إعادة النطبيق لتحديد مدى صدق المقياس حيث اختار الباحثون من من مجتمع البحث عدد ثلاثون عضوة من عثرة مراكز شباب من محافظة القاهرة وقام بنطبيق

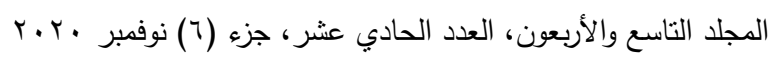




\section{مجلة العلوم البيئية \\ معهد الدراسات والبحوث البيئية - جامعة عين شمس له \\ باسر علي محمد وآخرون}

المقياس عليهن ثم قام بإعادة تطبيقه مرة أخرى عليهم بعد خمسة عثر يوماً وقد عالج الباحثون هذه البيانات عن طريق معادلة معامل الارتباط التالية:

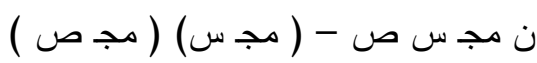

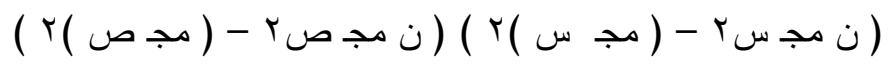

وبعد حساب صدق المقياس قام الباحثون بحساب ثبات المقياس بالنسبة للعينة الاستطلاعية

\begin{tabular}{|c|c|}
\hline Cronbanch`s Alpha & عدد افراد العينة \\
\hline$\cdot, 900$ & r. \\
\hline
\end{tabular}

حيث ان ألفا كرونباخ هو مقياس الاتساق الداخلي ، أب مدى ارتباط مجموعة من العناصر

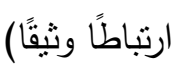

ثم قام الباحثون بتطبيق هذا المقياس ( مقياس المواطنة البيئية) عينة البحث قبل تطبيق البرنامج المقترح، وبعد الحصول على القياس القبلي تم تطبيق برنامج تتمية المواطنة البيئية

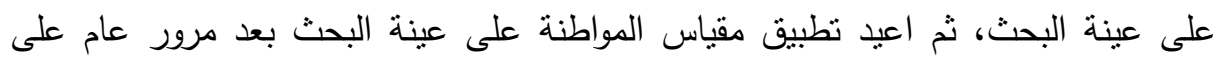
تطبيق برنامج تتمية المواطنة البيئية، ثم قام الباحثون بعمل المعالجات الاحصائية للتعرف لهن

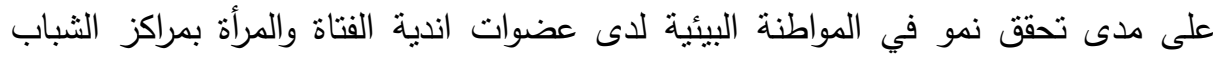
اللاتي طبق عليهن البرنامج من خلال المقارنة بين استجابتهن قبل تطبيق البرنامج وبعده. وبالإجابة على التساؤلات الفرعية الاربعة وما امكن التوصل اليه من نتائج يكون الباحثون قد توصلوا للإجابة على السؤال الرئيسي "ما فاعلية برنامج مقترح قائم على التعليم

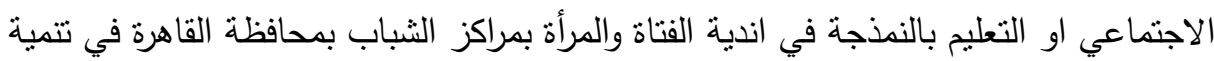

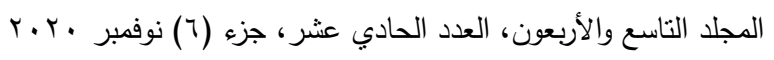

$$
\begin{aligned}
& \text { الترقيم الدولي 0826-1110 }
\end{aligned}
$$




\section{المعالجية الاجصائية}

استخدم الباحثون الاسلوب الوصفي نظرا لطبيعة البحث الذي يعتمد على وصف الواقع

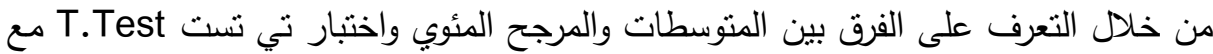
الاخذ في الاعتبار المقارنة بين كل مجموعة على حده والمقارنة بين كل مجموعة وباقي المجموعات والمقارنة بين اجمالي المجموعات قبل وبعد التطبيق وقياس مدى فاعلية اثر البرنامج من خلال معادلة الاثر لبلاك والمتمنلة فى المعادلة التالية:

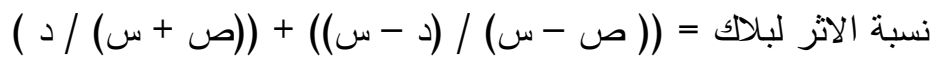

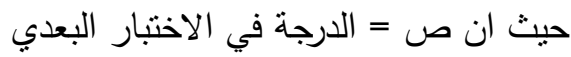
س = الدرجة في الاختبار القبلي د = النهاية العظىى للاختبار

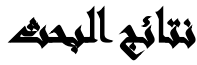

بالنسبة للسؤال الرئيس "'"ما فاعلية برنامج مقترح قائم على التعليم الاجتماعي او التعليم

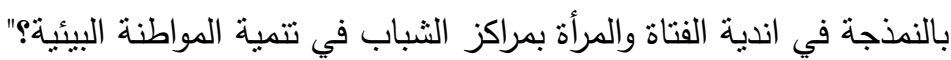
تبين من خلال المعالجة الاحصائية للمقارنة بين المتوسطات في القياس القبلي والقياس البعدى( بعد تطبيق البرنامج) ان البرنامج المقترح فعال ويؤدي الى تتمية المواطنة البيئية حيث ثبت وجود فروق جوهرية ذات دلالة احصائية بين القياس قبل تطبيق البرنامج وبعد تطبيق

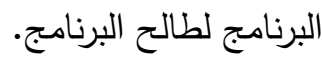
فالجداول التالية توضح الفروق الجوهرية الدالة احصائيا بين ما كان علية الوضع قبل تطبيق البرنامج وما اصبح عليه بعد تطبيق البرنامج.

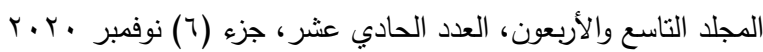

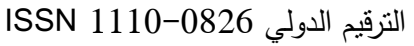


مجلة العلوم البيئية

معهد الدراسات والبحوث البيئية - جامعة عين شمس لهنه

ياسر علي محمد وآخرون

جدول (1) تأثير البرنامج على مفهوم المواطنة البيئية تبعاً للحالة التعليمية

\begin{tabular}{|c|c|c|c|c|c|c|c|}
\hline مستوي & المحسوية ت & المعياري & المئوجح & المرجح & العراد & \multicolumn{2}{|c|}{ تبهاً للحالة المواطنة } \\
\hline \multirow[b]{2}{*}{ دالة ا •, , } & \multirow{2}{*}{$1 \cdot, 9$} & I, & $\% 1 \cdot, 01$ & 11 & \multirow{2}{*}{$\wedge$} & قبل & \multirow{2}{*}{ امية } \\
\hline & & $r V, \Lambda$ & $\% \wedge r, r)$ & 10,0 & & بعد & \\
\hline \multirow{2}{*}{ دالة ا •,.• } & \multirow[t]{2}{*}{$1 \cdot, r$} & 7,09 & $\% \varepsilon, r$. & ir & \multirow{2}{*}{ rr } & قبل & \multirow{2}{*}{ تقرأ وتكتب } \\
\hline & & $\Lambda, r v$ & $\% \wedge 4, \cdot 1$ & $r \leq 7$ & & بعد & \\
\hline \multirow{2}{*}{ دالة ا •,. } & \multirow{2}{*}{$11, \varepsilon$} & $\varepsilon, T r$ & $\% q, \Gamma \varepsilon$ & IV & \multirow{2}{*}{$1 \varepsilon$} & قبل & \multirow{2}{*}{ الجامعي } \\
\hline & & $r_{1, \Lambda}$ & $\% 91, \vee 4$ & $17 \mathrm{~V}$ & & بعد & \\
\hline \multirow{2}{*}{ دالة ا •, • } & \multirow{2}{*}{9,71} & $r, r \leqslant$ & $\%$ \%,^० & $r$ & \multirow{2}{*}{7} & قبل & \multirow{2}{*}{ فاكثر } \\
\hline & & $r, T$ & $\% \wedge 0,9$. & TV & & بعد & \\
\hline \multirow{2}{*}{ دالة ا •, • } & \multirow{2}{*}{$1 \leqslant, r$} & $0, Y_{1}$ & $\% 4,74$ & $\varepsilon r$ & \multirow{2}{*}{0.} & قبل & \multirow{2}{*}{ التعليمية } \\
\hline & & $I V, V$ & $\% \wedge \vee,$. & 074 & & بعد & \\
\hline
\end{tabular}

يتبين من خلال الجدول رقم(1) الذي يعرض نتائج تأثثر البرنامج علي معرفة عضوات

اندية الفتاة والمرأة بمراكز الثباب لمفهوم المواطنة البيئية حيث توضح هذه النتائج وجود فروق جوهرية ذات دلالة احصائية بين التطبيق القبلي للبحث والتطبيق البعدي على مقياس المواطنة البيئية وذلك لصالح كل الفئات التعليمية التي خضعت للتين للبرنامج وقد دل على ذللك ارتفاع مؤشرات المتوسط المرجح والمتوسط المرجح المئوي والانحراف المعياري وقد اكد كل ذللك نتيجة اختبار تي تست (T.Test) حيث ان (ت) تكون دالة عند مستوى(ه •., ) اذا كانت

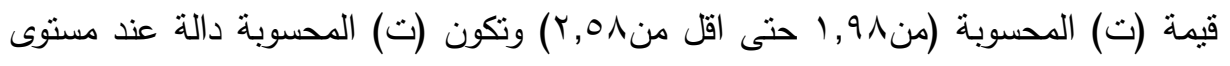

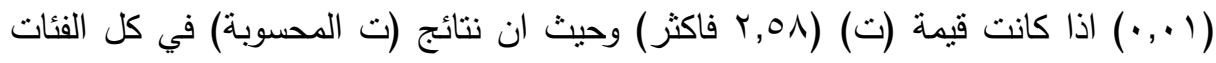
التعليمية اكثر من (Y,01) فان ذلك يدل على تأثير البرنامج على اكساب عضوات اندات اندية الفتاة 
مجلة العلوم البيئية

معهد الدراسات والبحوث البيئية - جامعة عين شمس لئن

باسر علي محمد وآخرون

والمرأة بمراكز الثباب لمفهوم المواطنة البيئية ، ويتفق ذلك مع ما توصلت اليه دراسة كل

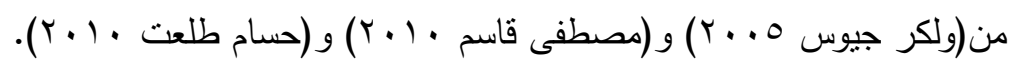

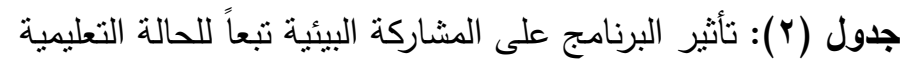

\begin{tabular}{|c|c|c|c|c|c|c|c|}
\hline مستوي & المحسوية ت & المعياري & المرئوسط & المرجح & المفردات & \multicolumn{2}{|c|}{ التبعارِكة اللحالئية } \\
\hline \multirow{2}{*}{ عند ال , , . } & \multirow{2}{*}{$9, r}$. & $1, V r$ & $\% 1, .01$ & 11 & \multirow{2}{*}{$\wedge$} & قبل & \multirow{2}{*}{ امية } \\
\hline & & Tr, & $\% \wedge r, r)$ & 10,0 & & بعد & \\
\hline \multirow{2}{*}{ عند ال , , . } & \multirow{2}{*}{$17,7}$. & $r, 7)$ & $\% \varepsilon, r$. & Ir & \multirow{2}{*}{ rr } & قبل & \multirow{2}{*}{ تقرأ وتكتب } \\
\hline & & $1 \cdot, 1$ & $\% \wedge 4, \cdot 1$ & $r \leqslant 7$ & & بعد & \\
\hline \multirow{2}{*}{ عند ال , , . } & \multirow{2}{*}{$1 \pi, .0$} & 0,17 & $\% q, r \leq$ & IV & \multirow{2}{*}{$1 \leq$} & قبل & \multirow{2}{*}{ الجامعي } \\
\hline & & 10,9 & $\% q 1, \vee 4$ & 178 & & بعد & \\
\hline \multirow{2}{*}{ عند ال ., . } & \multirow{2}{*}{9,77} & $7,0 \leqslant$ & $\%$ \%,^० & $r$ & \multirow{2}{*}{7} & قبل & \multirow{2}{*}{ فاكثري } \\
\hline & & 17,7 & $\% \wedge \bullet, q$. & TV & & بعد & \\
\hline \multirow{2}{*}{ عند ال , ,. } & \multirow{2}{*}{$11, .9$} & $\varepsilon, \cdot \wedge$ & $\% 4,7\}$ & $\varepsilon r$ & \multirow{2}{*}{0 . } & قبل & \multirow{2}{*}{ التعليمية } \\
\hline & & $1 \pi, 0$ & $\% \wedge \vee, \ldots$ & 074 & & بعد & \\
\hline
\end{tabular}

يتبين من خلال الجدول رقم(r) الذي يعرض نتائج تأثير البرنامج علي معرفة عضوات

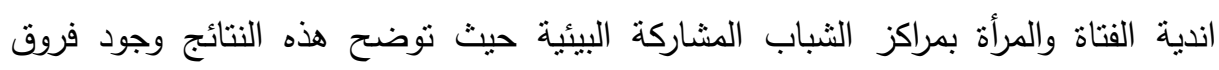
جوهرية ذات دلالة احصائية بين النطبيق القبلي للبحث والتطبيق البعدي على مقياس المواطنة

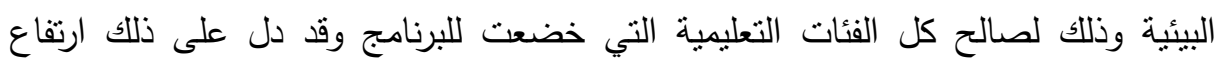
مؤشرات المتوسط المرجح والمنوسط المرجح المئوي والانحراف المعياري وقد اكد كل ذللك نتيجة اختبار تي تست (T.Test) حيث ان (ت) تكون دالة عند مستوى(0. •. •) اذا كانت

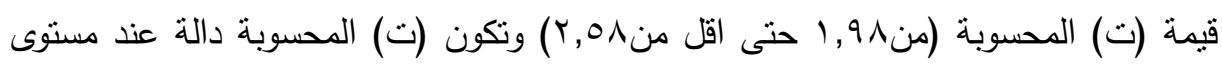

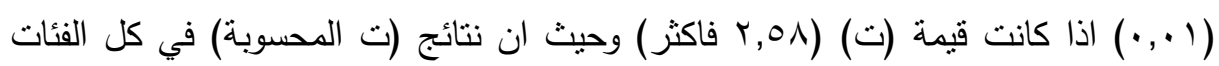

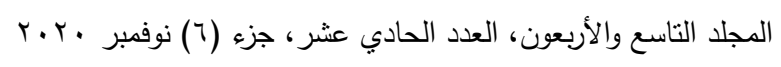


مجلة العلوم البيئية

معهد الدراسات والبحوث البيئية - جامعة عين شمس ليفه

ياسر علي محمد وآخرون

التعليمية اكثر من (Y,01) فان ذلك يدل على تأثير البرنامج على زيادة قدرة عضوات اندية

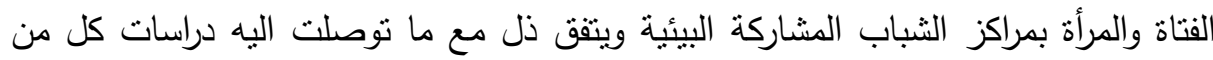

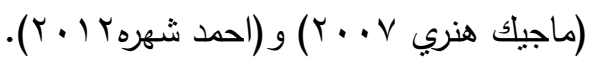

جدول (r): تأثثر البرنامج على المسئولية الثخصية او العمل الجماعي تبعاً للحالة التعليمية

\begin{tabular}{|c|c|c|c|c|c|c|c|}
\hline مستوى الدلاكة & المحسوية & الانحراف & المرجح المئويط & المرجح المبط & المفردات & & 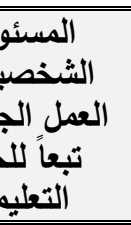 \\
\hline \multirow{2}{*}{ دالة عند ا · ,. } & \multirow{2}{*}{$q, \wedge \vee$} & $7, \cdot 1$ & $\% 1 \cdot, 0 \wedge$ & 11 & \multirow{2}{*}{$\wedge$} & قبل قبل & \multirow{2}{*}{ امية } \\
\hline & & $1 V, \varepsilon$ & $\% \wedge r, Y)$ & 10,0 & & بعد & \\
\hline \multirow{2}{*}{ دالة عند ا • , • } & \multirow{2}{*}{ IV,r } & $0, \Gamma_{\Lambda}$ & $\% \varepsilon, r$. & ir & \multirow{2}{*}{ rr } & قبل قبل & \multirow{2}{*}{ تقرأ وتكتب } \\
\hline & & 11 & $\% \wedge 7, \cdot 1$ & $r \leq 7$ & & بعد & \\
\hline \multirow{2}{*}{ دالة عند ا •, • } & \multirow{2}{*}{ Ir, } & 0,17 & $\% q, r \leq$ & iv & \multirow{2}{*}{$1 \varepsilon$} & قبل & \multirow{2}{*}{ الجامعي } \\
\hline & & IV,r & $\% 91, \vee 7$ & 178 & & بعد & \\
\hline \multirow{2}{*}{ دالة عند ا • , • } & \multirow{2}{*}{1.} & $\wedge, \uparrow \wedge$ & $\%$ \%,^० & $r$ & \multirow{2}{*}{7} & قبل قبل & \multirow{2}{*}{ فاكثر } \\
\hline & & $I V, V$ & $\% \wedge 0,9$. & $7 V$ & & بعد & \\
\hline \multirow{2}{*}{ دالة عند ا •, • } & \multirow{2}{*}{$1 \wedge, 7$} & $0, \vee 7$ & \%ч,тr & $\varepsilon r$ & \multirow{2}{*}{0.} & قبل قبل & \multirow{2}{*}{ التعليمية } \\
\hline & & $1 \varepsilon, 9$ & $\% \wedge \vee, \ldots$ & 077 & & بعد & \\
\hline
\end{tabular}

يتبين من خلال الجدول رقم(r) الذي يعرض نتائج تأثير البرنامج علي قدرة عضوات

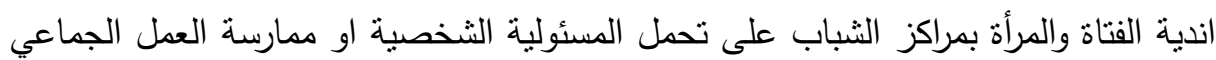
حيث توضح هذه النتائج وجود فروق جوهرية ذات دلالة احصائية بين النطبيق القبلي للبحث

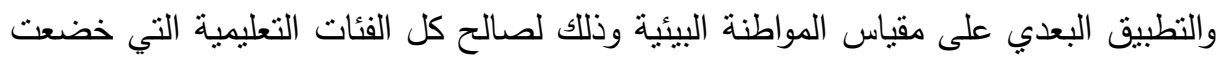
للبرنامج وقد دل على ذللك ارتفاع مؤشرات المتوسط المرجح والمتوسط المرجح المئوي والانحراف المعياري وقد اكد كل ذلك نتيجة اختبار تي تست (T.Test) حيث ان (ت) تكون 262

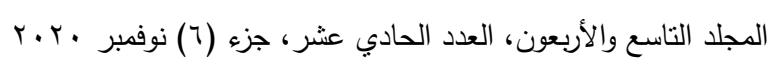


مجلة العلوم البيئية

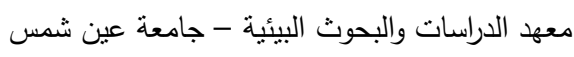

ياسر علي محمد وآخرون

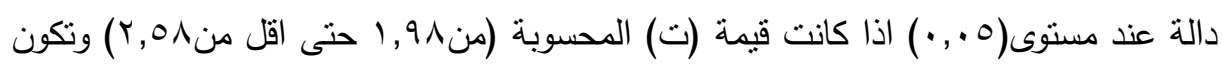

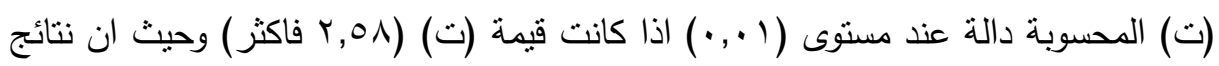

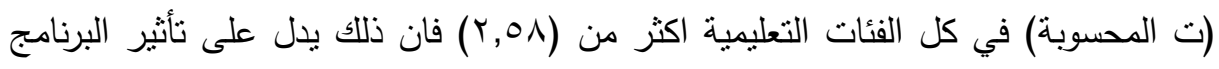

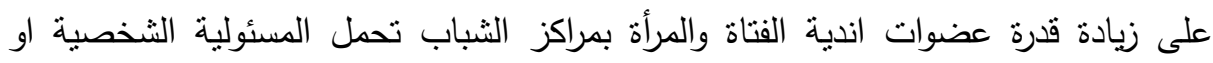
المشاركة في العمل الجماعي ويتفق ذلك مع ما توصلت اليه دراسات(محمد العجوز \99 (1) )

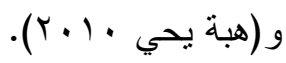

جدول (ء): تأثثر البرنامج على ممارسة العدالة البيئية تبعاً للحالة التعليمية

\begin{tabular}{|c|c|c|c|c|c|c|c|}
\hline الدلالةّ & المحسوية ت & المعياري & المتوجي & المرجح & المفردات & \multicolumn{2}{|c|}{ البعاُ للعالةل التعماعيّية } \\
\hline \multirow{2}{*}{ عند ا +, , . } & \multirow{2}{*}{$\mid r, 01$} & 17,94 & $\% 1,, 01$ & 11 & \multirow{2}{*}{$\wedge$} & قبل & \multirow{2}{*}{ امية } \\
\hline & & $\curlyvee \wedge, \wedge \uparrow$ & $\% \wedge r, r)$ & 10,0 & & بعد & \\
\hline \multirow{2}{*}{ عند ال , , } & \multirow{2}{*}{$r \cdot, \cdot r$} & $1,0 r$ & $\% \varepsilon, r$. & Ir & \multirow{2}{*}{ rr } & قبل & \multirow{2}{*}{ تقرأ وتكتب } \\
\hline & & $17, r q$ & $\% \wedge 4, \cdot 1$ & $r \leq 4$ & & بعد & \\
\hline \multirow{2}{*}{ عند ال , , . } & \multirow{2}{*}{$11, \cdot 1$} & $11, \cdot v$ & $\% q, r \leq$ & IV & \multirow{2}{*}{$1 \varepsilon$} & قبل & \multirow{2}{*}{ الجامعي } \\
\hline & & $r \varepsilon$ & $\% q 1, \vee\urcorner$ & 178 & & بعد & \\
\hline \multirow{2}{*}{ عند ال ,. } & \multirow{2}{*}{$1 T, 94$} & YY, rY & $\%$ \%,^० & $r$ & \multirow{2}{*}{7} & قبل & \multirow{2}{*}{ فاكثري } \\
\hline & & $r v, 0 \leqslant$ & $\% \wedge 0, q$. & TV & & بعد & \\
\hline \multirow{2}{*}{ عند ال ,., } & \multirow{2}{*}{$r T, Y r$} & $11,7 r$ & \%ч, тr & $\varepsilon r$ & \multirow{2}{*}{0.} & قبل & \multirow{2}{*}{ التعليمية } \\
\hline & & YY, $\Sigma \varepsilon$ & $\% \wedge \vee, .$. & 070,0 & & بعد & \\
\hline
\end{tabular}

يتبين من خلال الجدول رقم(ع) الذي يعرض نتائج تأثنير البرنامج علي ممارسة عضوات

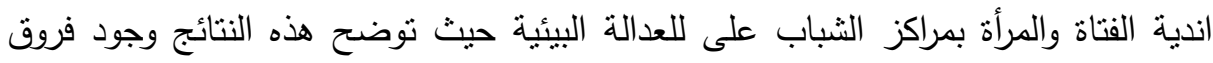
جوهرية ذات دلالة احصائية بين التطبيق القبلي للبحث والتطبيق البعدي على مقياس المواطنة البيئية وذللك لصالح كل الفئات التعليمية التي خضعت للبرنامج وقد دل على ذلك ارتفاع

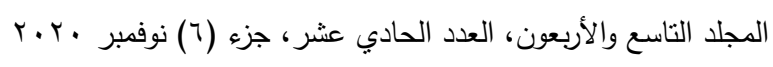


مؤشرات المتوسط المرجح والمتوسط المرجح المئوي والانحراف المعياري وقد اكد كل ذلك نتيجة اختبار تي نست (T.Test) حيث ان (ت) تكون دالة عند مستوى(ه). , •) اذا كانت

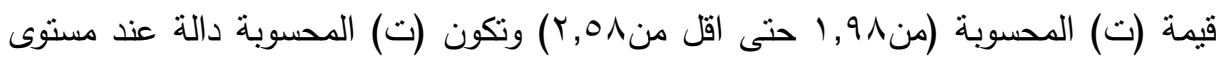

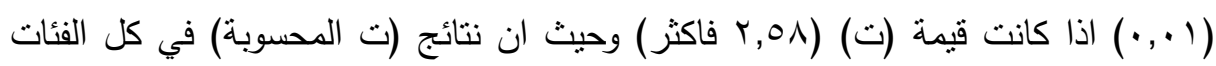

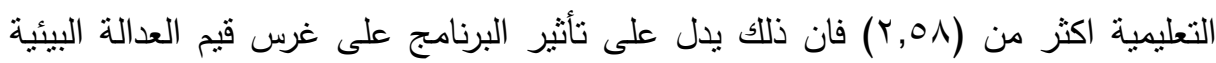
لاى عضوات اندية الفتاة والمرأة بمراكز الثباب ويفق ذلك مع ما نوصلت اليه دانيه دراسات (بيتر

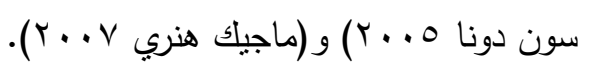

\section{اللزوسيايت}

ا ـ تطبيق برنامج نتمية المواطنة البيئية بكافة اندية الفتاة والمرأة بمراكز الثباب.

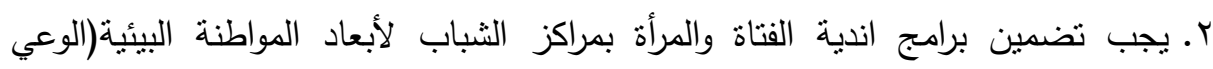

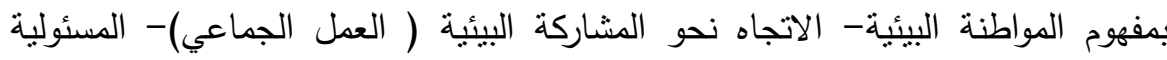
الثخصية البيئية - الاتجاه نحو العدالة البيئية)

r. نشر الوعي بالحقوق والواجبات البيئية لدى عضوات اندية الفتاة والمرأة بمراكز الثباب.

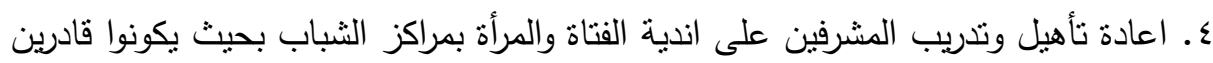
على بث وغرس وتتمية المواطنة البيئية لدى عضوات اندية الفتاة والمرأة بمراكز الثباب. ه. نشجيع ابتكار انشطة وبرامج لأندية الفتاة والمرأة تتضمن مفاهيم وابعاد المواطنة البيئية.

\section{المرانيع}

إبراهيم ناصر (r . r): المواطنة، دار مكتبة الرائد العلمية، عمان.

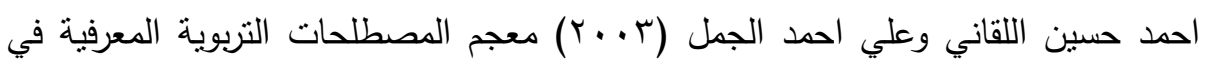

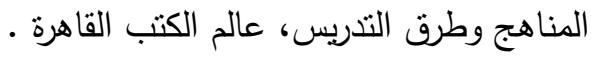

أحمد عبد اللطيف ابو اسعد. (11 (1). تعديل السلوك الإنساني - النظرية والتطبيق. عمان: دار المبيرة للنشر والتوزيع والطباعة. (النئ. 
أحمد عبدالملك محمد شهده(Y r. r): دور الأندية ومراكز الثباب في تفعيل المشاركة

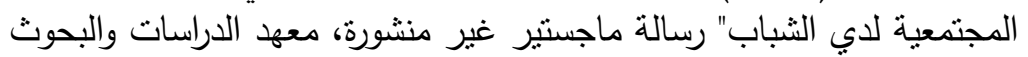

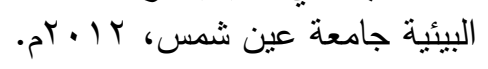

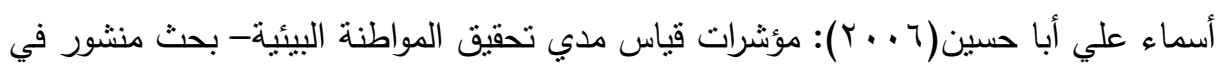
مجلة العلوم الاجتماعية- العدد ب- بـ مجلس النشر العلمي جامعة الكويت.

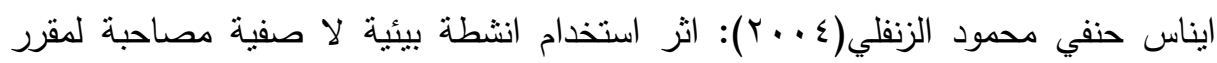

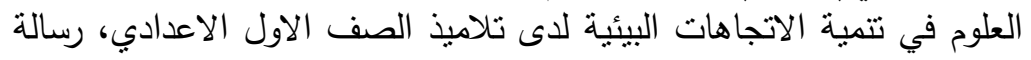

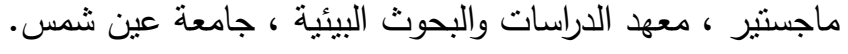

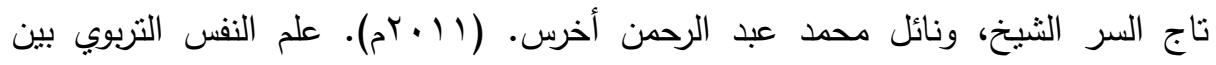

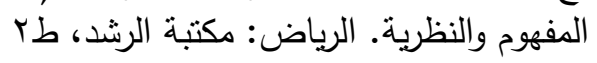

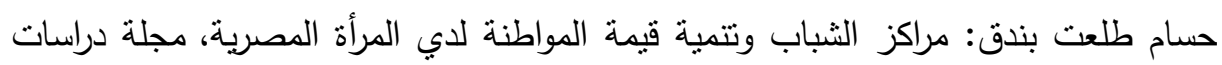

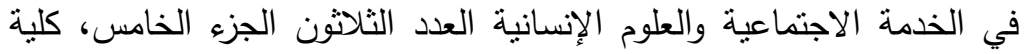

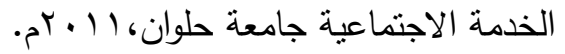

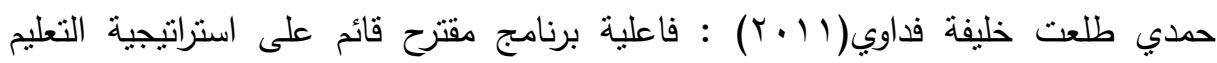

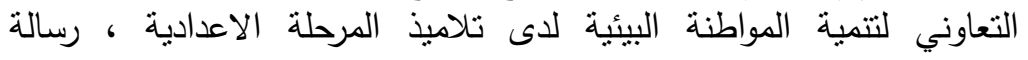
ماجستير - معهد الدراسات والبحوث البيئية - جامعة عين شمس .

خليل ميخائيل معوض(999(1)): علم النفس الاجتماعي، الاسكندرية، دار الفكر الجامعي، (

رشاد عبد اللطيف(999 (1)): طريقة تتظيم المجتمع في الخدمة الاجتماعية ، المكتب الجامعي

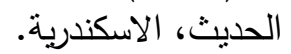

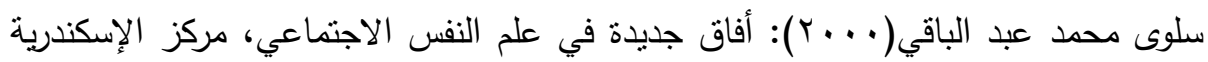

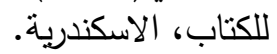

عبد العزيز عبد الهه مختار (ب99 (1)): بحوث الخدمة الاجتماعية، دار الحكيم للنشر، القاهرة.

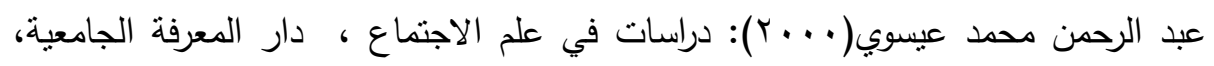
الإسكندرية. 
عبد الحليم رضا عبد العال وآخرون(|99 (19): نماذج ونظريات تتظيم المجتمع ، دار الحكيم،

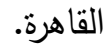

عدنان العتوم، شفيق علاونه، والجراح، عبد الناصر الجراح (ع ا • rم). علم النفس التربوي

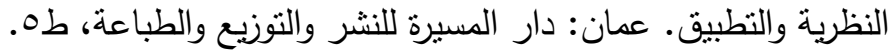

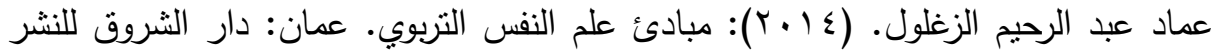
والتوزيع، طه.

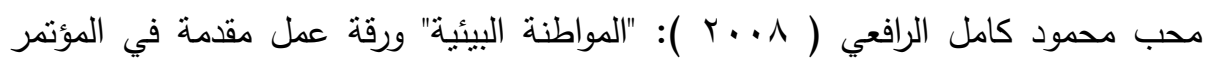
القومي للتوعية والارشاد من مخاطر التلوث البيئي، مشروع المواطنة البيائية، المركز الثقافي، وزارة الدولة لشئون البئئة. محمد، محمود مندوه. (11 + آم). نظريات التعلم.: مكتبة الرشد ،الرياض.

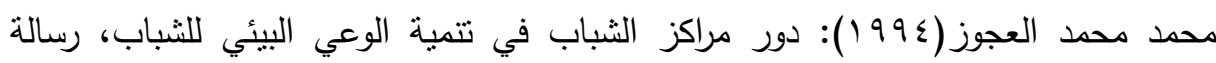

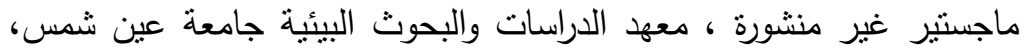
. 999

مصطفى محمد قاسم(• (ب): إسهام مراكز الثباب في تدعيم قيم المواطنة لاى الثباب،

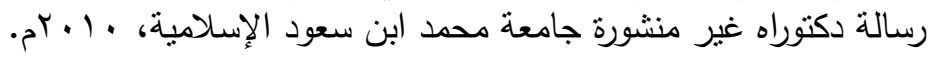

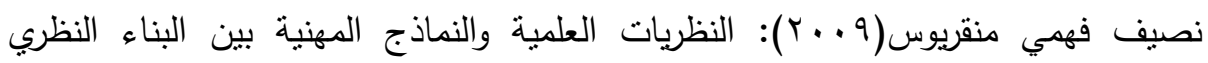

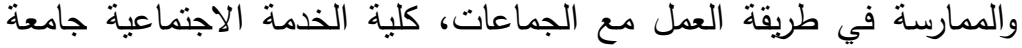
حلوان.

هبه يحيي حسن عوض: مسئولية المؤسسات الثبابية في تفعيل الفتبات نحو البيئة" دراسة

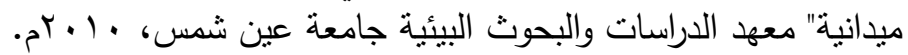

(1) Skye Lander - Kimberly:(2004) A description of adult environmental education programs inresidential environmental education centers: Their use of experiential learning theory and environmental citizenship concepts, Phd, university- of-Idaho,USA,,pg143.

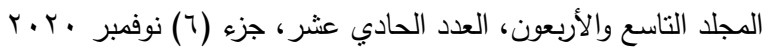

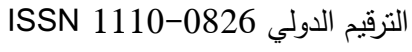




$$
\begin{aligned}
& \text { مجلة العلوم البيئية } \\
& \text { معهد الدراسات والبحوث البيئية - جامعة عين شمس } \\
& \text { ياسر علي محمد وآخرون }
\end{aligned}
$$

(2) Petesron Donna: Pathways of influence in out of school time Community University partnership to develop Ethics new directions for youth development/2005

(3) Walker Joyce: shaping Ethics Youth workers matter. new directions for youth development, Journal Articles Reports descriptive American 2005.

(4) Magick Hanray: post 16 citizenship in colleges an introduction to effective practice, learning and skills network, united state, 2007.

\title{
THE EFFECTIVENESS OF GIRL AND WOMAN CLUB IN YOUTH CENTERS FOR DEVELOPING ENVIRONMENTAL CITIZENSHIP"
}

\author{
Yasser A.Mohamed ${ }^{(1)}$; Moheb M. K. Al-Rafei ${ }^{(2)}$ \\ and Mosaad S. Ewies ${ }^{(3)}$
}

1) Post Grad., student, Institute of Environmental Studies and Research, Ain Shams University 2) Institute of Environmental Studies and Research, Ain Shams University 3) Educational Science, Faculty of physical Education Helwan University.

\footnotetext{
ABSTRACT

The aim of the current research is to identify the extent of the effectiveness of the girls 'and women's clubs program in youth centers in Cairo governorate in developing environmental citizenship, as well as to overcome the negatives that hinder its effectiveness and to develop a vision for developing environmental citizenship through the girls' and women's clubs in youth centers.

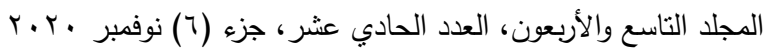

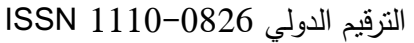




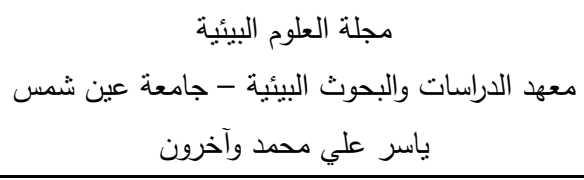

A program for the development of environmental citizenship was set up in the girls 'and women's clubs in youth centers in Cairo governorate, and this program was applied to a group of fifty members in the girls' and women's clubs in youth centers (Mr. Zainab - AlQubbah - Al-Amiriya - Ahmed Esmat), where an application of the environmental citizenship scale was implemented The component of four basic dimensions (the concept of environmental citizenship environmental participation - personal responsibility or collective action - environmental justice) before the implementation of the proposed program and then re-apply the environmental citizenship measure to them after the completion of the implementation of the program, which was applied at the rate of one session every month each One of the four girls' and women's clubs on which the program was applied over a period of twelve months, and the first session was devoted to the preapplication of the scale, and the twelfth session was devoted to ending the program and conducting the post application, while the sessions from the second to the eleventh were dedicated to the proposed program and the general objective was For the program to develop environmental citizenship among members of the girls' and women's clubs in youth centers in Cairo governorate, using the cooperative education strategy, as for the sub-goals of For the program, it consisted in the member of the girls' and women's clubs in the youth centers able to determine:

The concept of environmental citizenship - dimensions of environmental citizenship - environmental participation - environmental justice - personal responsibility towards the environment - working in a team to protect the environment

When preparing the program, the researchers took into account the following:

Dimensions of environmental citizenship - characteristics of the age stage of female and girl club members (from 18 years to 35 years) the nature of the society in which the program will be implemented.

$$
\begin{aligned}
& \text { r.r. المجلد التاسع والأربعون، العدد الحادي عثر ، جزء (T) نوفمبر }
\end{aligned}
$$

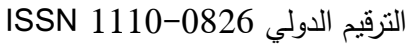




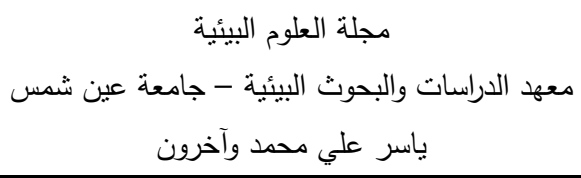

The experimental method was used in this research with a quasiexperimental design.

The results of the research proved that there are deficiencies in the programs offered in the girls 'and women's clubs in the youth centers in developing environmental citizenship, and that the program prepared for the development of environmental citizenship has greatly contributed to the development of environmental citizenship among young people, and this was evident through the results of the research after the implementation of the proposed program, Where it was found that there are statistically significant differences in environmental citizenship among members of the girls' and women's clubs in youth centers to whom the program was applied.

The research recommended the following:

1 .The implementation of the environmental citizenship development program in all girls' and women's clubs in youth centers.

2 .The programs of the girls' and women's clubs in the youth centers must be included for the dimensions of environmental citizenship (awareness of the concept of environmental citizenship - the trend towards environmental participation (team work) - personal environmental responsibility - the trend towards environmental

3 .Rehabilitation and training of supervisors for girls 'and women's clubs in youth centers, so that they are able to transmit, instill and develop environmental citizenship among members of the girls' and women's clubs in youth centers.

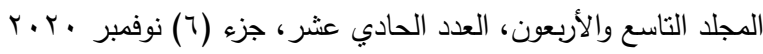

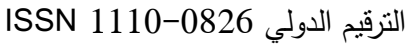

